\title{
ANALOG-MODEL SIMULATIONS FOR SECONDARY CANAL CONTROLS AND FORWARD PUMPING WATER-MANAGEMENT SCHEMES IN SOUTHEAST FLORIDA
}
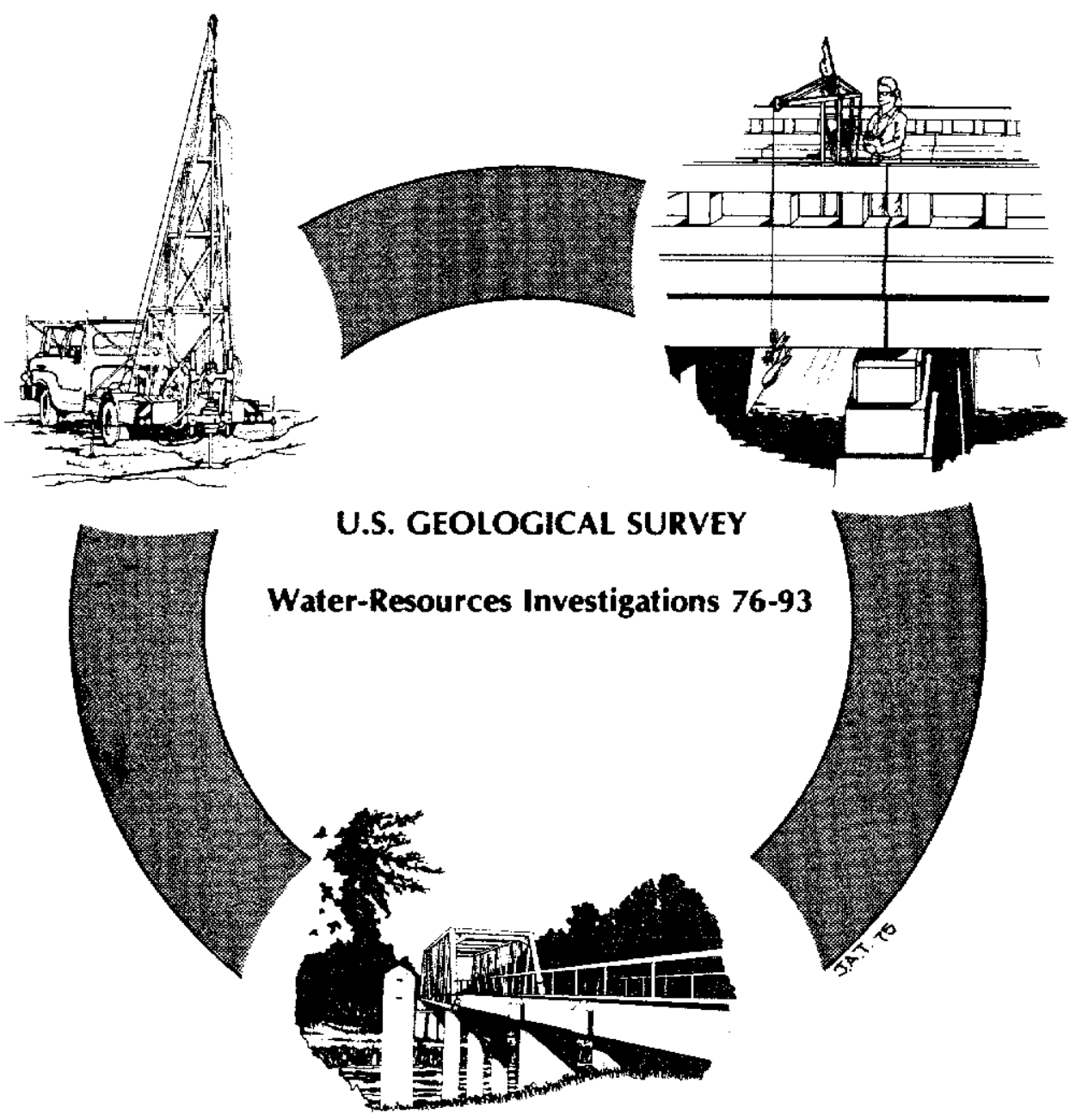

Prepared in cooperation with CENTRAL AND SOUTHERN FLORIDA FLOOD CONTROL DISTRICT 


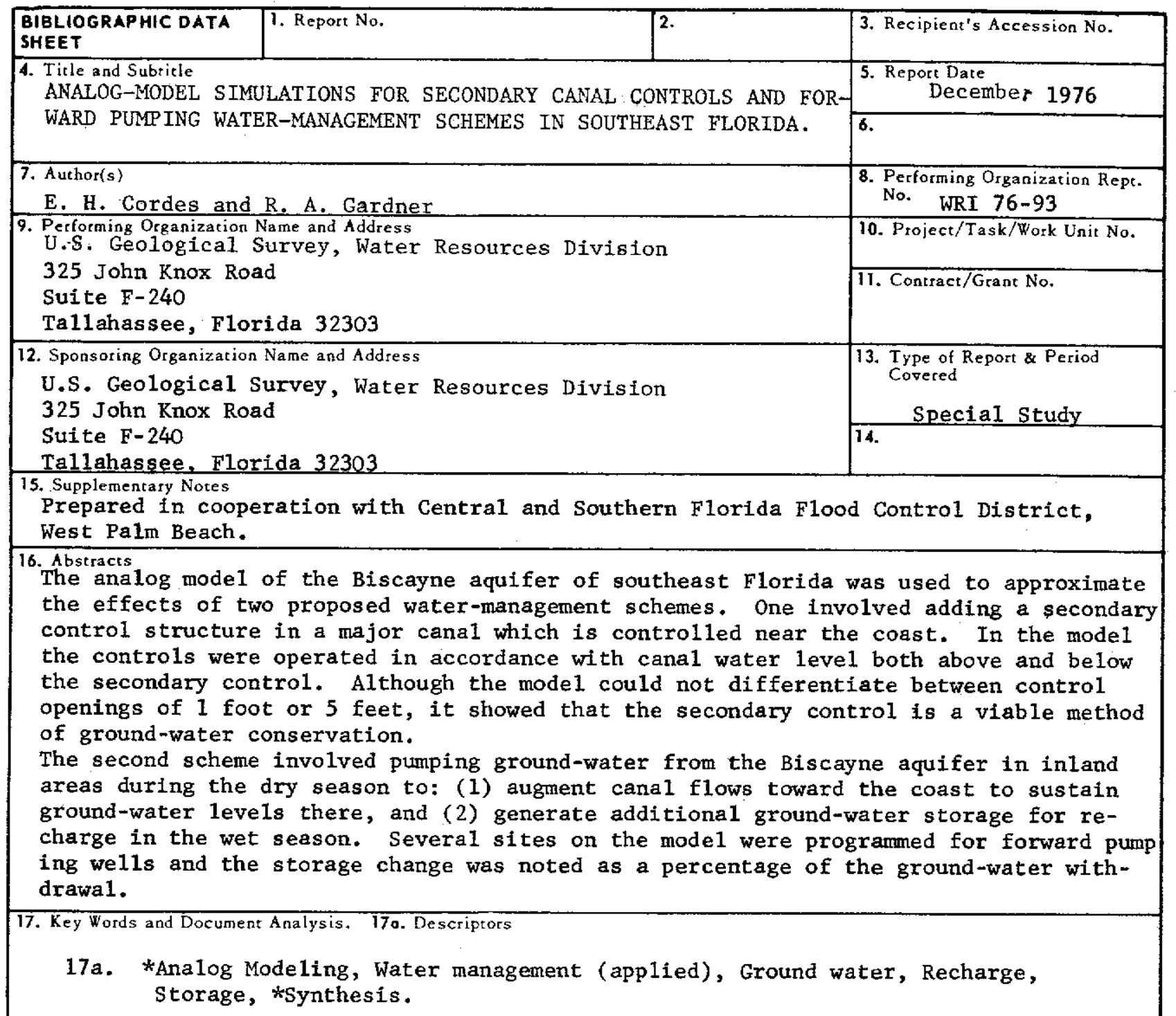

17b. Identifiers/Open-Ended Terms

*Biscayne Aquifer, Secondary control structure, Forward pumping, *Everglades (Florida).

17c. COSATI Field/Group

\begin{tabular}{|c|c|c|}
\hline 18. Availability Scatement & $\begin{array}{l}\text { 19. Security Class (This } \\
\text { Report) } \\
\text { UNCLASSIFIED }\end{array}$ & $\begin{array}{c}\text { 21. No. of Pages } \\
68\end{array}$ \\
\hline No restriction on distribution & $\begin{array}{l}\text { 20. Security Class (This } \\
\text { Page } \\
\text { UNCLASSIFIED }\end{array}$ & 22. Price \\
\hline
\end{tabular}


ANALOG-MODEL SIMULATIONS FOR SECONDARY CANAL CONTROLS

AND FORWARD PUMPING WATER-MANAGEMENT SCHEMES

IN SOUTHEAST FLORIDA

By E. H. Cordes and R. A. Gardner

U.S. GEOLOGICAL SURVEY

Water-Resources Investigations 76-93

Prepared in cooperation with the CENTRAL AND SOUTHERN FLORIDA FLOOD CONTROL DISTRICT 
UNITED STATES DEPARTMENT OF THE INTERIOR

Thomas S. Kleppe, Secretary

GEOLOGICAL SURVEY

V. E. McKelvey, Director

For additional information write to:

U.S. Geologica1 Survey

325 John Knox Road, F-240

Tallahassee, Florida 32303 
Abstract . . . . . . . . . . . . . . . . . . . . 1

Introduction .......................... 1

Purpose and scope . . . . . . . . . . . . . . . . 3

Previous studies ..................... 3

Methods of analysis ..................... 3

Proposal for secondary controls in canals . . . . . . . . . 6

Mode1 design ................... 7

Analysis of simulations ................ 19

Summary ........................ 33

Proposal for forward pumping . . . . . . . . . . . . . 33

Model design ..................... 34

Analysis of simulations .................. . . . 38

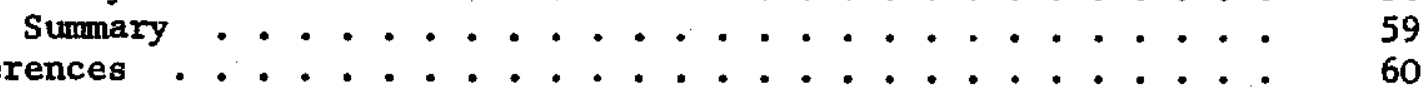

\section{ILLUSTRATIONS}

Figure 1.--Map of location of secondary control model basin on analog model ..................

2.--Map of location of forward pumping test sices on analog mode1

3.--Map showing the physical geometric boundaries, model grid matrix and other hydrologic features of the Snake Creek canal drainage basin . . . . . . . .

4.--Diagram showing electric analog mechanism to simulate a proportional control structure . . . . . . .

5.--Graph showing canal flow through a proportional control structure computed from equation No. 2 ....

6.--Diagram showing time distribution of precipitation in Snake Creek canal drainage basin . . . . . . . .

7.--Graph showing relation of evapotranspiration (ET) to water-table depth ..................

8.--Contour map of secondary control mode1, base level potentiometric surface - condition 1 , run $74-38$. .

9.--Contour map of secondary control mode1, base leve1 potentiometric surface - condition 2, run 74-40 . . . 


\section{ILLUSTRATIONS (Cont'd.)}

Figure 10-17.--Contour maps of secondary contro1 mode1, 6-month

change from base-level condition for model group:

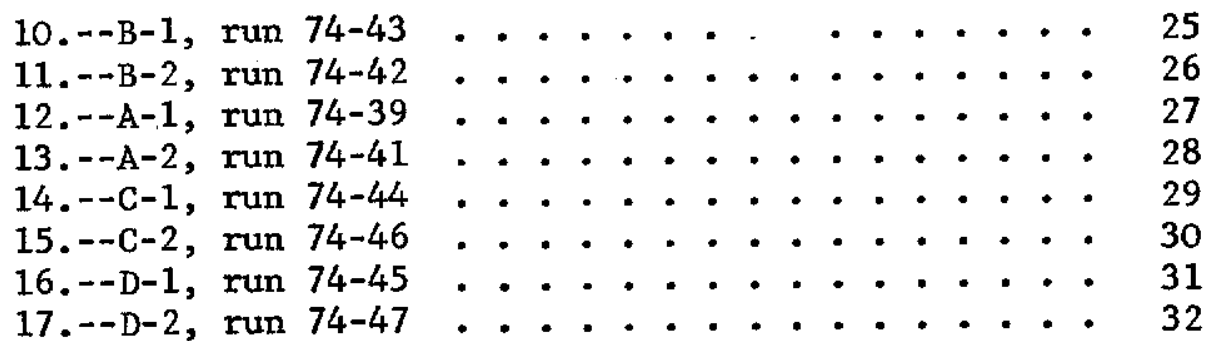

Figure 18.--Map showing forward pumping sample areas on analog mode1

19.--Hydrographs for ground-water we11 G-1165 and model node $B N-92$ in test site $A A ; A$, Field data from well G-1165; B, Initial condition simulation; C, Forward pumping simulation. . . . . . . . . . . . . .

20.--Effect of forward pumping stress $(\Delta h D)$ observed at a typica1 mode1 node

Figure 21-25.--Graphs showing percentage of standard sampling area for which $\left(\Delta \mathrm{h}_{\mathrm{D}}\right)$ was equal to or less than the indicated value for forward pumping simulation:

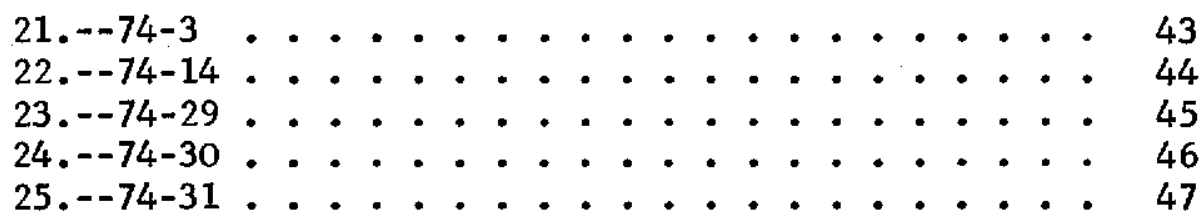

Figure 26-35.--Contour maps of median value head changes $\left(\Delta \mathrm{h}_{\mathrm{D}}\right)$ for forward pumping simulation:

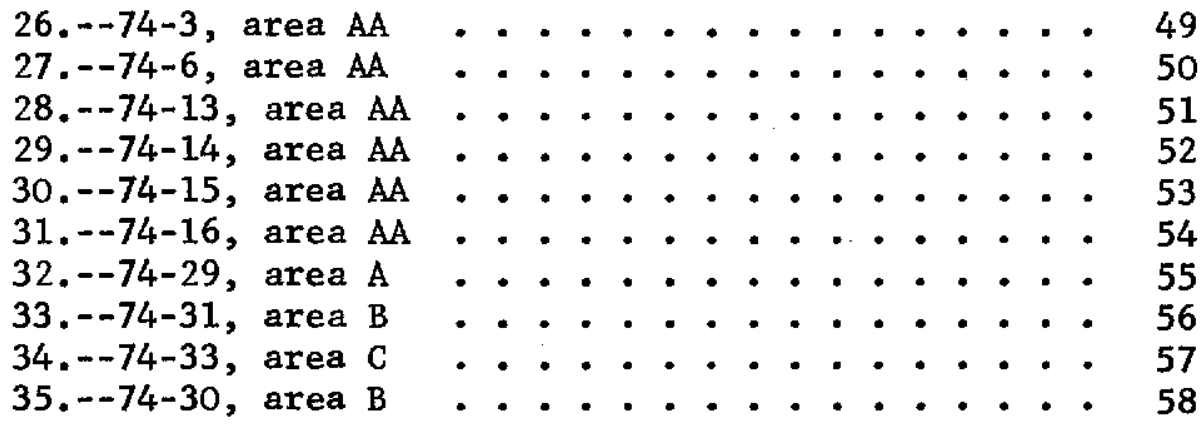


Table 1.--Mean water levels on basin boundaries for 1970-71... .

2.--Operating schedules for control structure gate openings ....................... 14

3.--Computed rainfall for analog model simulations from published data at station Pensuco 5-NW, Miami . . . . 16

4.--Net recharge (Rp) by area for rainfall conditions exceeded 90 percent of the time, secondary control mode1

5.--Estimated ground-water withdrawals from various pumping centers in the model basin, prorated from Miami well field records for 1970-71 . . . . . . . . .

6.--Water budget for 6-month period in units $\times 10^{8}$ gallons . 21

7.--Summary of forward pumping simulations . . . . . . . 36

8.--Programed data to forward pumping mode1 . . . . . . . 37

9.--Mass balance of forward pumping simulations, 6-month changes from base level condition ........... 40 
AND FORWARD PUMPING WATER-MANAGEMENT SCHEMES

IN SOUTHEAST FLORIDA

By

E. H. Cordes and R. A. Gardner

\begin{abstract}
The analog model of the Biscayne aquifer of southeast Florida was used to approximate the effects of two proposed water-management schemes. one involved adding a secondary control structure in a major canal which is controlled near the coast. In the model the controls were operated in accordance with canal water level both above and below the secondary control. Although the model could not differentiate between control openings of 1 foot or 5 feet ( 0.3 metre or 1.5 metres), it showed that the secondary control is a viable method of conserving ground water.

The second scheme involved pumping ground water ("forward pumping") from the Biscayne aquifer in inland areas during the dry season to: (1) augment canal flows toward the coast to sustain ground-water levels there, and (2) generate additional ground-water storage space for recharge in the wet season. Several sites on the model were programed for forward pumping wells and the storage change was noted as a percentage of the ground-water withdrawal.
\end{abstract}

\title{
INTRODUCTION
}

The primary source of water for populous southeast Florida is the Biscayne aquifer, which is composed of highly permeable limestone, and sandy limestone and sand (Parker and others, 1955). The aquifer is wedgeshaped, thickening to the east where it is hydraulically connected to the sea. Toward the west the aquifer thins and interfingers with the muck and mar1 that underlie the Everglades.

Before the 1900's natural freshwater springs discharged from the aquifer along the coast and water supplies were obtained from shallow wells near Biscayne Bay. Early in the 20th century the Miami River was deepened and extended inland, which accelerated drainage and lowered the freshwater. head in the aquifex in adjacent areas. The construction of additional canals in the area caused further general lowering of the freshwater head. A landward movement of saltwater in the aquifer finally resulted in the need to drill municipal water supply wells in inland, uncontaminated parts of the aquifer.

Uncontrolled drainage resulted in a wide advance of the saltwater wedge into the aquifer by 1946 which caused severe water-supply problems 
(Parker and others, 1955). At that time a series of temporary dams were constructed in canals connected to the bay. These dams reduced freshwater runoff to the ocean, and maintained higher freshwater heads in the aquifer, and thus stabilized the inland movement of saltwater.

As development continued and the demands for additional drained land grew, more canals were constructed or existing canals were extended. The regional surface drainage systems were extended inland and expanded to include large water-conservation areas. The conservation areas provide temporary storage for excess rainfal1 during the wet season. During the dry season water from Lake Okeechobee and the conservation areas is released to supply the urban and agricultural needs, and to maintain the freshwater head along the coast as a means of stabilizing the salt-water front.

Gradually the temporary coastal dams in canals were replaced with control structures which regulated canal flow to the bay. Secondary control structures, inland of the coastal controls were constructed on a few major canals.

A11 of these facilities constitute a complex hydrologic system whose management becomes increasingly difficult as greater stresses are imposed on it. The Central and Southern Florida Flood Control District, a management agency, is responsible for its operation, and is actively engaged in seeking new techniques to maximize water management. Because of the complexity of the system many management problems do not lend themselves readily to direct mathematical solution.

Insight to solution of these problems may be obtained by use of an electrical analog simulation model of the system in which actual parameters are approximated. The U.S. Geological Survey, in cooperation with the Central and Southern Florida Flood Control District and the National Park Service, has constructed an electrical analog model (Appe1, 1973), which has been used to assess the effects of various water-managment schemes.

For use of those readers who may prefer to use metric units rather than English units, the conversion factors for the terms used in this report are listed below:

\section{MuItiply English unit}

inch (in)

feet $(f t)$

mile (mi)

gallon (gal)

gallon per minute (gal/min) million gallon per day (Mgal/d)

cubic feet per second $\left(\mathrm{ft}^{3} / \mathrm{s}\right)$

$\underline{\text { By }} \quad \underline{\text { To obtain metric unit }}$

25.4

0.3048

1.609

.003785

.0000631

.04381

.02382 millimetre (mm)

metre (m)

kilometre $(\mathrm{km})$

cubic metre $\left(\mathrm{m}^{3}\right)$

cubic metre per second $\left(\mathrm{m}^{3} / \mathrm{s}\right)$

cubic metre per second $\left(\mathrm{m}^{3} / \mathrm{s}\right)$

cubic metre per second $\left(\mathrm{m}^{3} / \mathrm{s}\right)$ 
The purpose of this investigation is to evaluate, through electrical analog model simulation, the effects of two specific water-management proposals primarily in Dade County; (1) the installation of a secondary control on Snake Creek Canal, and (2) the forward pumping scheme. Figures 1 and 2 show extent of areas modeled in the foregoing two proposals.

Both management proposals are sufficiently complex to warrant the use of the electric analog model for simulation. Each problem was programed separately into the existing electrical analog model of the Biscayne aquifer (Appe1, 1973).

\section{Previous Studies}

Parker and others (1955) included a comprehensive study of the geology and hydrology of Dade County with emphasis on the Biscayne aquifer and its hydraulic characteristics in their study of the water resources of southeastern Florida. Hydraulic characteristics of the aquifer were evaluated by Klein and Sherwood (1961), Sherwood and Leach (1962) and Leach and Sherwood (1963). Kohout and Leach (1964) reported on saltwater movement in the Snake Creek Canal and its effects on ground water in the vicinity of the canal as the result of operation of the coastal control structure.

The physical characteristics and hydrologic aspects of a flood-control plan for an inland part of Dade County and its possible effects on urbanization of the area were discussed by Kohout and Hartwe11 (1967). Included in that report is a description of a steady-state analog mode1, used to evaluate the effects of the flood control plan. This early model was used to evaluate the effects from canals, pumps, plugs and controls at various locations in the canal network. In the evaluation, the authors suggested that more sophisticated transient-state resistor-capacitor (passive element) analog models of the Biscayne aquifer were needed for more accurate and definitive evaluations. Such a model was constructed in the early $1960^{\prime} \mathrm{s}$. Appe1 (1973) discusses the design and construction of the electrical analog model. The data used to define aquifer characteristics and the corresponding model coefficients were obtained from the reports cited, and from various unpublished records. Flow data for the canals, ground-water levels and pumping data from major well fields were obtained from records collected before model construction.

\section{METHODS OF ANALYSIS}

Interpretation of all modeling problems are subject to the constraints of both the model and the data. The method of interpretation can be objective and analytical. While the attempt is made to construct models that are reasonable portrayals of "real-world" situations, simplifications are required where data and methods are lacking. Initial results of modeling efforts are only a first approximation of the cause and effect relationships that exist in the real system. Adjustments to the model, which are necessary to replicate dynamic changes observed in the field, must bear reason- 


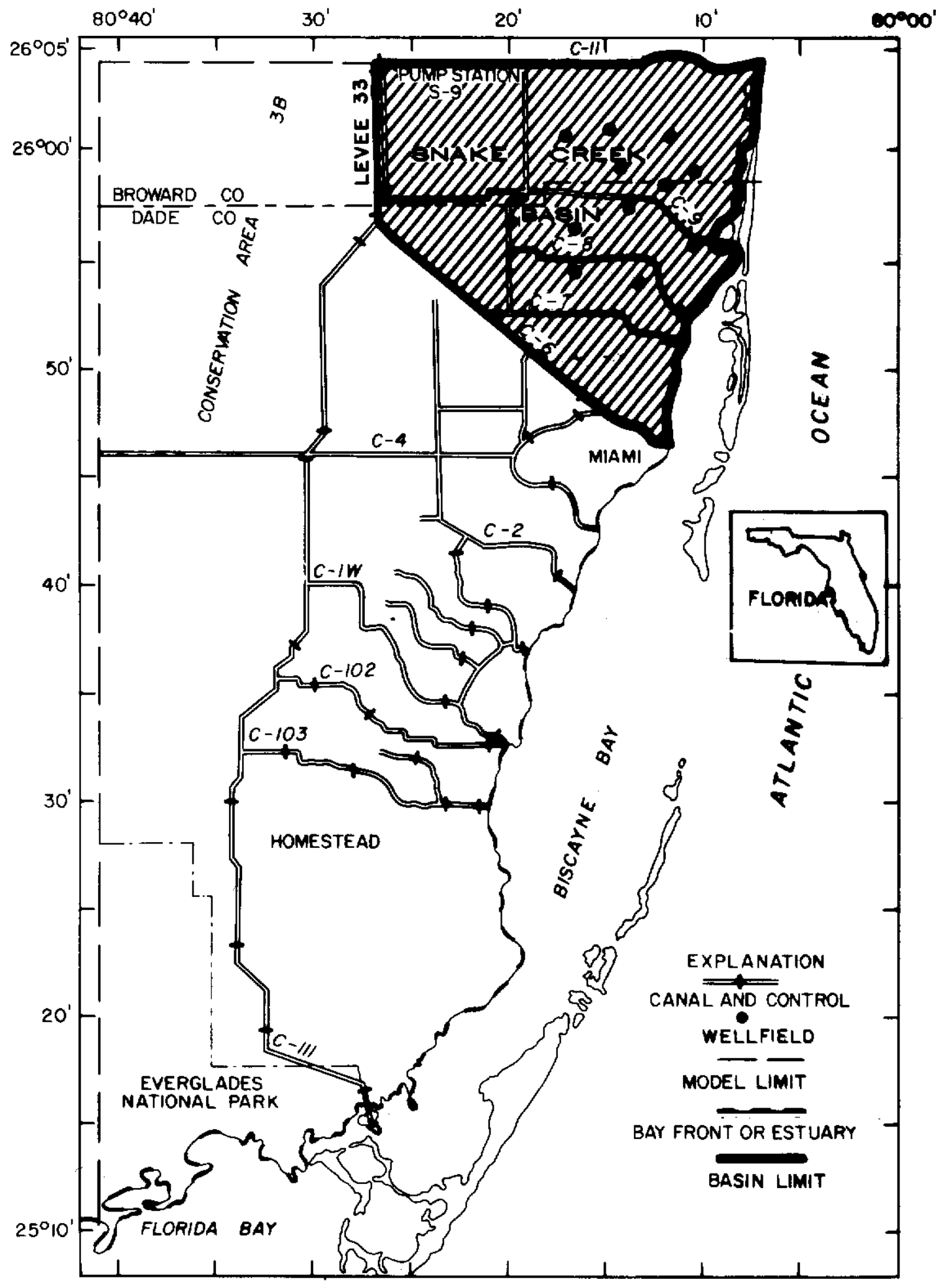

Figure 1.--Location of secondary control model basin on analog model. 


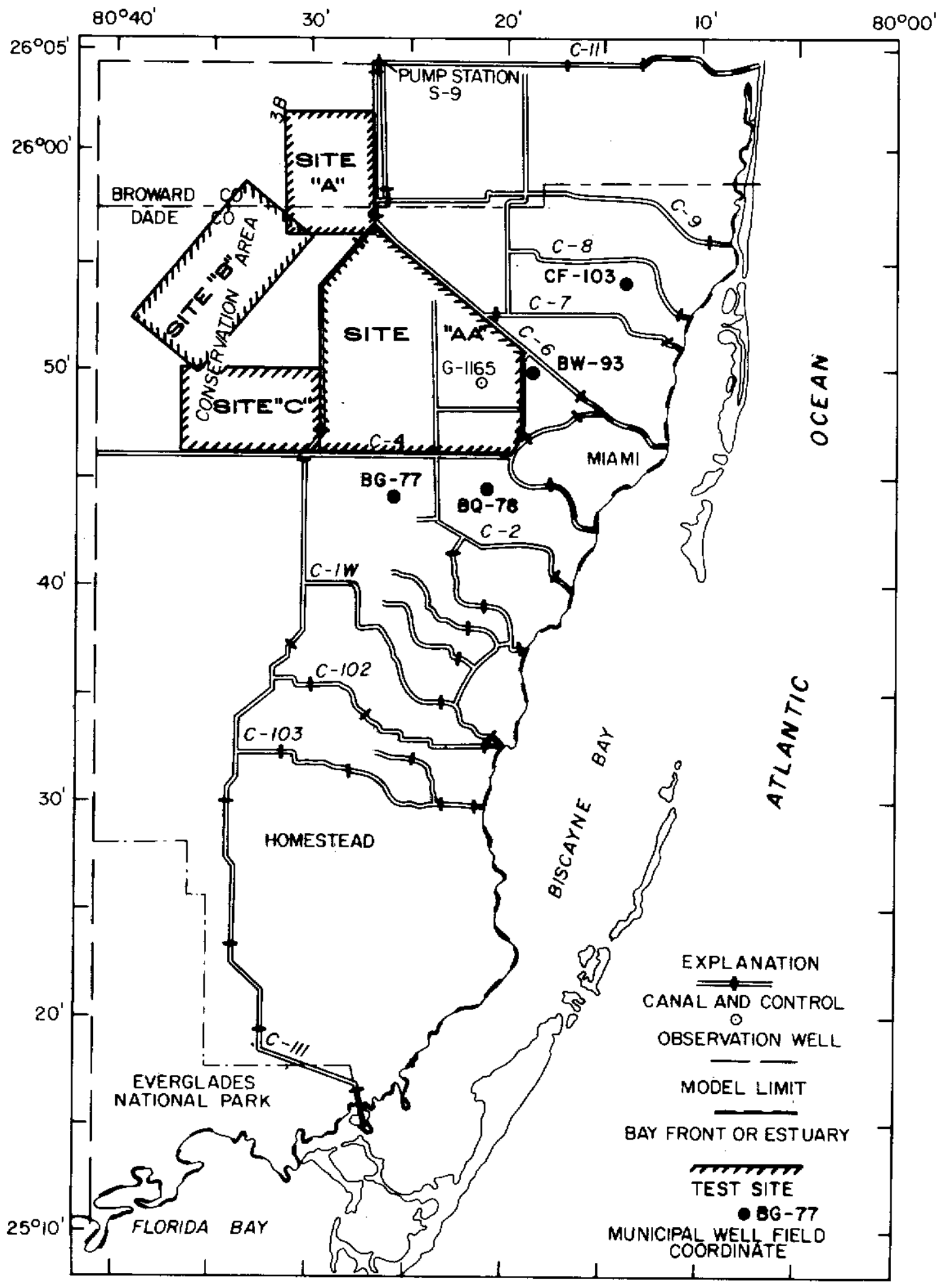

Figure 2.--Location of forward pumping test sites on analog mode1. 
able credance to the parameters and functions that describe the flow of water as a free surface or through a porous medium. Application of special simulation techniques are needed to relate the Biscayne aquifer model to the hydraulic conditions that exist in south Florida. Principal constratits of the model are found in the treatment of a) boundary conditions, b) groundwater and surface-water interface, c) surface-water ponding, and d) canal conveyance. A11 of these factors must be simplified in the analog model design. Ground-water flow is adequately handled, but the surface-water conditions are difficult to simulate. Water levels above ground surface, a condition which exists for several months each year in south Florida, is not adequately simulated in the model. Although the electronic mechanism to simulate ponding is available, the functional relations which would eventually distribute ponded water through infiltration, evaporation or canal flow cannot be readily defined.

Further complications are encountered in modeling cana1 water levels and canal flow which cannot be described simultaneously as independent variables. That is, in simulation of canals on the model either the head or level of the canal can be established and the change in canal flow can be measured, or the flow can be maintained and the canal level measured. These limitations require judicious programing of the model.

A trial and error approach is used to define the limits of the model to resolve differences in programed data, determine the mode1 sensitivity, and establish a maximum, or optimum management solution. Several variations of each of the model studies were simulated for comparative purposes.

In practice the model simulates an appropriate part of the hydologic cycle. The management scheme is then imposed on the model for the same test period and a comparison of the results is made. Specific details of the initial conditions and the test simulations are discussed in the following sections of this report.

The mathematical concept of superposition was used in these analyses for comparisons of initial condition situations and test runs, and for evaluating the various pumping configurations with respect to each other. Some statistical procedures were employed (as later explained) to convert raw data into suitable input to the analog mode1, and in the final analysis of data obtained from forward pumping simulations.

\section{PROPOSAL FOR SECONDARY CONTROLS IN CANALS}

One objective of this investigation is to determine if placement of a secondary control structure in Snake Creek Canal, a major canal in north Dade County, is a viable means of water conservation and flood protection for the basin. At present, water control in the Snake Creek basin is accomplished by operation of the coastal control structure. The eastern half of the basin is urban and suburban but the remainder sparsely suburban or undeveloped. It seemed evident that the installation and operation of a secondary control structure near the middle of the reach would permit lowering of canal levels and adjacent ground-water levels in the urban-suburban 
areas for flood control, and at the same time retard drainage from the inland reach, thereby increasing water conservation. The canal would continue to provide flood protection but it would also reduce fresh-water losses to the ocean.

\section{Mode1 Design}

The model simulation is designed to test operational schemes and maximize inland ground-water storage through the operation of control structure gate openings. Constraints on the operation of the control structures are dictated by canal water levels.

The Snake Creek Canal basin is bounded by the South New River Canal $(\mathrm{C}-11)$ on the north, levee 33 of Conservation Area $3 \mathrm{~B}$ on the west, the Miami Canal (6-C) on the south and Biscayne Bay on the east. Figure 3 shows the geometry of the basin, the main boundary features, grid network, pumping centers, and the control locations. The canal boundaries are assumed to be recharge sources to the ground-water system. The water levels at these boundaries are either held constant or are programed to change as a function of time.

The canal system shown in figure 1 is greatly simplified in figure 3 where only one canal, Snake Creek Cana1 (C-9), is modeled within the boundaries. Simulation of the hydraulic connection between the canal and the ground-water system is accomplished by lumping the effect of the parameters that control interface impedance. This impedance to flow between ground water and surface water is approximated electrically by a passive element resistor equivalent to the reciprocal of areal vertical flux per unit of head according to the following mathematical expression:

$$
\begin{aligned}
& \mathrm{R}_{\mathrm{z}}=\frac{\mathrm{I}}{\mathrm{C}_{\mathrm{V}}}=\frac{\mathrm{T}}{\mathrm{P}_{\mathrm{V}}(\mathrm{W}+2 \mathrm{D}) \mathrm{L}} \cdot \frac{\mathrm{K}_{3}}{\mathrm{~K}_{2}} \text { where } \\
& \mathrm{C}_{\mathrm{V}}=\text { vertical flux in }(\mathrm{gal} / \mathrm{d}) \cdot \mathrm{ft}-1 \\
& \mathrm{R}=\text { electrical resistance, in ohms. } \\
& \mathrm{T}=\text { thickness of impeding material, in } \mathrm{ft} . \\
& \mathrm{P}_{\mathrm{V}}=\text { vertical permeability, in (gal/d) } \mathrm{ft}-2 \\
& (\mathrm{~W}+2 \mathrm{D}) \text { = wetted canal perimeter, in ft. } \\
& \mathrm{L}=\text { canal length, in ft } \\
& \mathrm{K}_{3}=\text { scaling coeficient, }(\mathrm{gal} / \mathrm{d}) \cdot \mathrm{amp}-1 \\
& \mathrm{~K}_{2}=\text { scaling coeficient, } \frac{\mathrm{ft}}{\mathrm{volt}}
\end{aligned}
$$

The primary (coastal) control structures, S-13 on $\mathrm{C}-11$ canal and S-26 


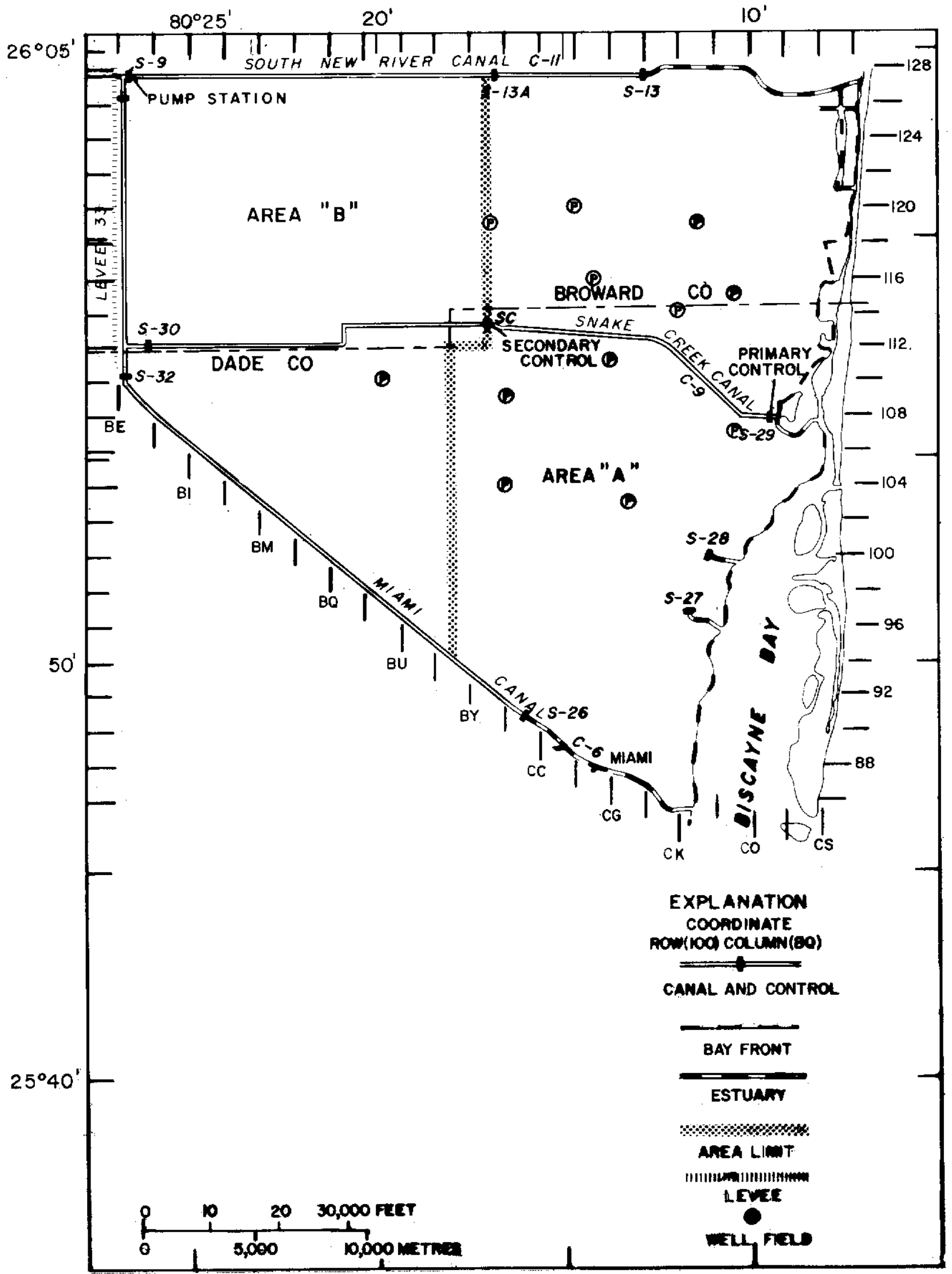

Figure 3.--Physical geometric boundaries, model grid matxix and other hydrologic features of the Snake Creek Canal drainage basin. 
on Miami Canal, are modeled with switches, either full on or full off. For all tests these two controls were assumed to be closed, as were controls $\mathrm{S}-13 \mathrm{~A}, \mathrm{~s}-30, \mathrm{~s}-32, \mathrm{~s}-27$ and $\mathrm{s}-28$. The primary contro1 $\mathrm{s}-29$ and the proposed secondary control (SC) on Snake Creek Canal are modeled as time dependent proportional controls. Locations of these control structures are shown on figure 3 .

The model was programed to simulate hydrologic conditions under which the control structures probably would operate. The base level condition represents the beginning of the dry season at the end of October 1972 (Hu11 and Wimberly, 1972), when water levels were about $5 \mathrm{ft}(1.5 \mathrm{~m})$ above ms 1 (mean sea level) along the west boundary with a gradually declining gradient toward the east boundary.

The boundaries of the Snake Creek basin were programed with the month1y water levels shown in Table 1 except for Biscayne Bay which, through necessity, was modeled at a constant level $0.5 \mathrm{ft}(0.15 \mathrm{~m})$ above $\mathrm{ms} 1$. Originally, a tidal simulation was tried for the bayfront boundary; the time relating coefficient, $K_{t}$, of $2.89 \times 10^{9}$, between the electric analog model and the real world, required a model frequency of 7,608 kilohertz (KHz) to simulate the tide cycle. The average range of the full wave tide cycle is about $2.5 \mathrm{ft}(0.76 \mathrm{~m})$ or 1 volt in the electric analog model. At this amplitude and frequency the passive element, RC (resistor-capacitor), network of the model is less than 100 ohms impedance; thus, current demands for tidal simulation exceeded the capacity of available current generating amplifiers. It became necessary to approximate the tidal boundary condition by a direct current voltage of 0.2 volt, equivalent to the root-mean-square value of the tide function.

A proportional control structure in the electric analog is a passive element that can regulate canal discharge according to a set of operating criteria. A control structure which is closed represents an infinite impedance to flow. In the analog model this is simulated by opening the canal conductor bus using a switch or relay. A schematic representation of the electronic proportional control mechanism is shown in figure 4. opening of the control switch will restrict the canal flow in its upper reach, thus retarding the drainage process. Cana1 discharge through a proportional control structure is approximated by the following expression,

$$
\begin{aligned}
& Q=C A \sqrt{2 g \Delta h} \\
& Q=\text { Cana1 flow in } \mathrm{ft}^{3} / \mathrm{s} \\
& \mathrm{C}=\text { Contraction coefficient, a constant }=0.72 \\
& A=\text { Area of gate opening in } \mathrm{ft} . \\
& \mathrm{g}=\text { Acceleration of gravity in } \mathrm{ft} / \mathrm{s}^{2}
\end{aligned}
$$

$\Delta h=$ Difference between upstream and downstream water levels in ft. 
Table 1.--Mean water levels on basin boundaries for 1970-71.

Boundary-Section

\begin{tabular}{c} 
Feet above \\
mean sea leve1 \\
\hline 1970 1971 \\
Nov. Dec.
\end{tabular}

South New River Canal (C-11)*

$\begin{array}{llllll}1.88 & 1.82 & 1.75 & 1.69 & 1.62 & 1.56\end{array}$

Levee 33 Cana1 - Conservation Area 3B

$\begin{array}{llllll}7.16 & 6.66 & 6.16 & 5.66 & 5.16 & 4.66\end{array}$

Miami Canal $(C-6)$

$\begin{array}{llllll}2.27 & 2.08 & 1.89 & 1.69 & 1.50 & 1.31\end{array}$

* Data from records downstream of control S-13A. 


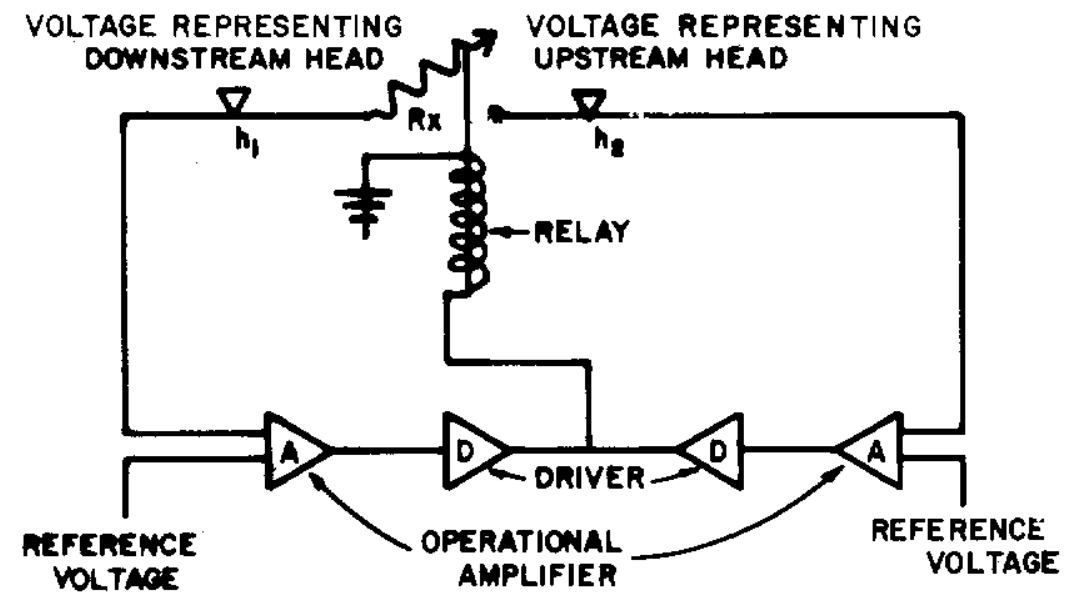

RK = PASSIVE ELEMENT TO REGULATE FLOW

A - SENSING AMPLIFIER TO CONTROL GATE OPERATION D- DRIVER

Figure 4.--Electric analog mechanism to simulate a proportional control structure. 
The width of the control structure is $50 \mathrm{ft}(15 \mathrm{~m})$. The flow is directly proportional to the gate opening and the square root of the difference in water levels. This relationship, in turn, is modeled by two linear functions as shown in figure 5, using discrete resistor elements.

The operation of a proportional control structure is predicated on fixed canal levels above and below the structure that reflect some assumed flood criteria but also must prevent over drainage as a water conservation measure. Table 2 shows the status of the gating portion chosen for this study. Only one condition allows for both the primary and the secondary control to be open at the same time, and at no time are both controls closed simultaneously except between changes of state.

Other programed parameters consist of rainfall (a major source of recharge to the basin), ground-water withdrawal, (pumping) and evapotranspiration losses as a function of depth to water.

A design rainfall was developed from stations with 30 or more years of record. Statistical analyses of these records are the basis of the design rainfa11. Total rainfall for November through April (dry season) was analyzed for each station record. On the basis of frequency analysis of these data, the total dry season rainfall that could be expected to be exceeded 90 percent of the time was determined (Benson and Gardner, 1973). The mean value for the period of record was also determined for comparison. These values were used to determine weighted values of rainfall over the study area. The results are shown in figure 6 and table 3 .

The time distribution of rainfall (fig. 6) shows two quite different patterns. As expected, the mean value of rainfall distribution is modulated toward an inverted gaussian curve whereas the extreme distribution has a pronounced "S" shape. Although a zone of high rainfall does exist inland from the ocean, it did not significantly influence the rainfall distribution which is assumed to be uniform within the basin.

Only a part of the rainfall incident on the Snake Creek Canal basin recharges the ground-water system. Because areas $A$ and $B$ (fig. 3) differ in land use and therefore rainfall infiltration potential, the amount of recharge shown in figure 6 and table 3 is computed by applying the recharge factor ( $f$ ) of 0.50 for area $B$ and 0.25 for area $A$. Net recharge to the ground-water system programed into all of the secondary control model simulations is shown in table 4 .

Discharge from the ground-water system is by pumping for municipal and other uses, by evapotranspiration, and by coastal under seepage. Pumping rates for municipalities within the basin, shown in table 5, were computed by weighted monthly ratios based on pumping records of the Miami well field for 1970-71. These withdrawals were applied to the mode1 at specific node intersections on the RC network, as indicated in table 5 and shown on figure 3 .

Losses attributed to ET (evapotranspiration) are described by an as- 


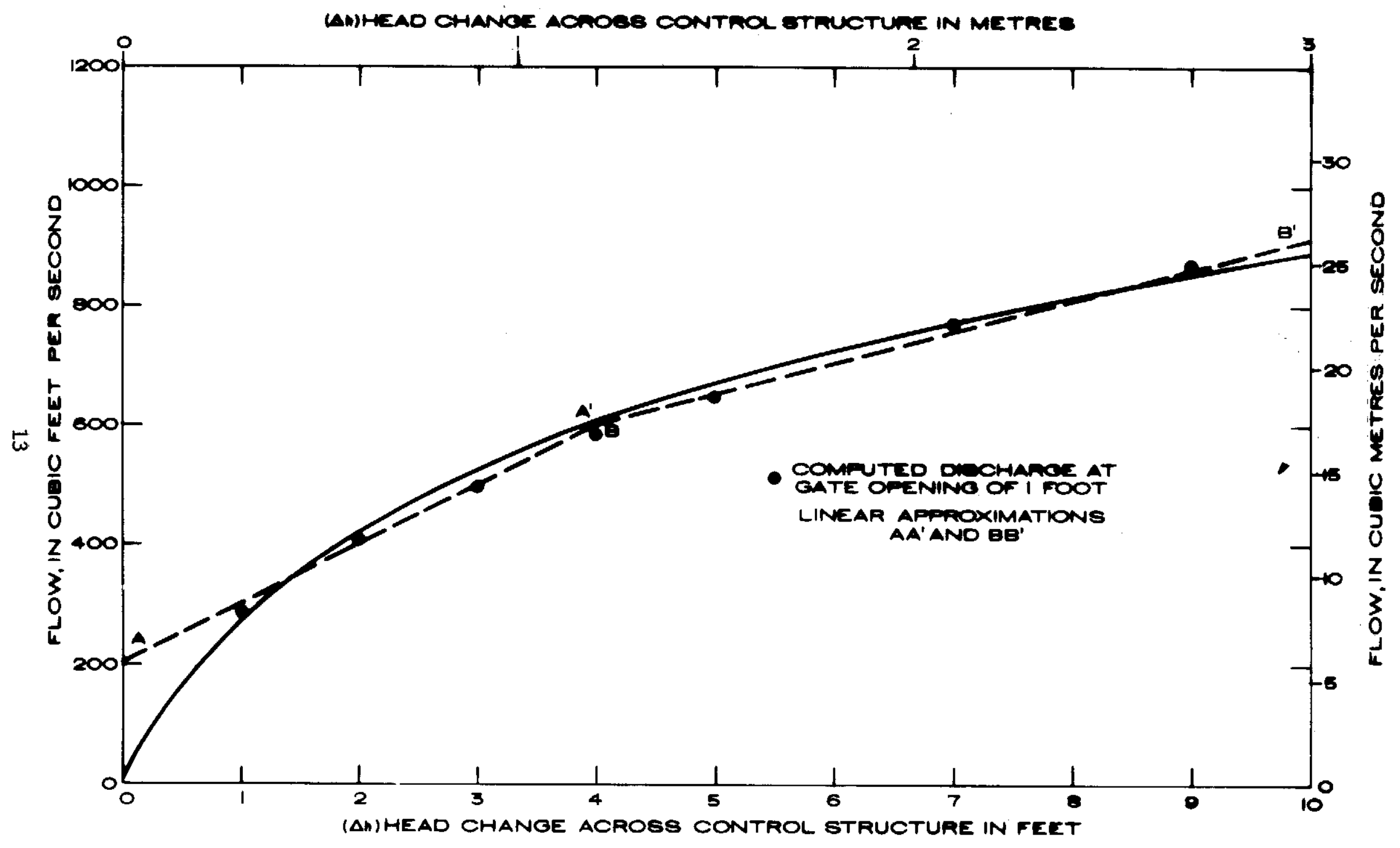

Figure 5.--Canal flow through a proportional control structure computed from equation No. 2. 
Table 2.--Operating schedules for control structure gate openings.

\section{Primary Contro1}

Upstream canal leve1, feet above ms 1

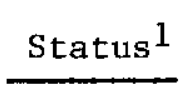

Greater than

2.5

2.5

2.5

Less than

2.5

Greater than

Less than

1 O, open; C, closed.

o

\section{Secondary Control}

Upstream canal leve1, feet above ms 1

Status

Greater than

4

0

Greater than

4

o

Less than

4

0

Less than

4

C 


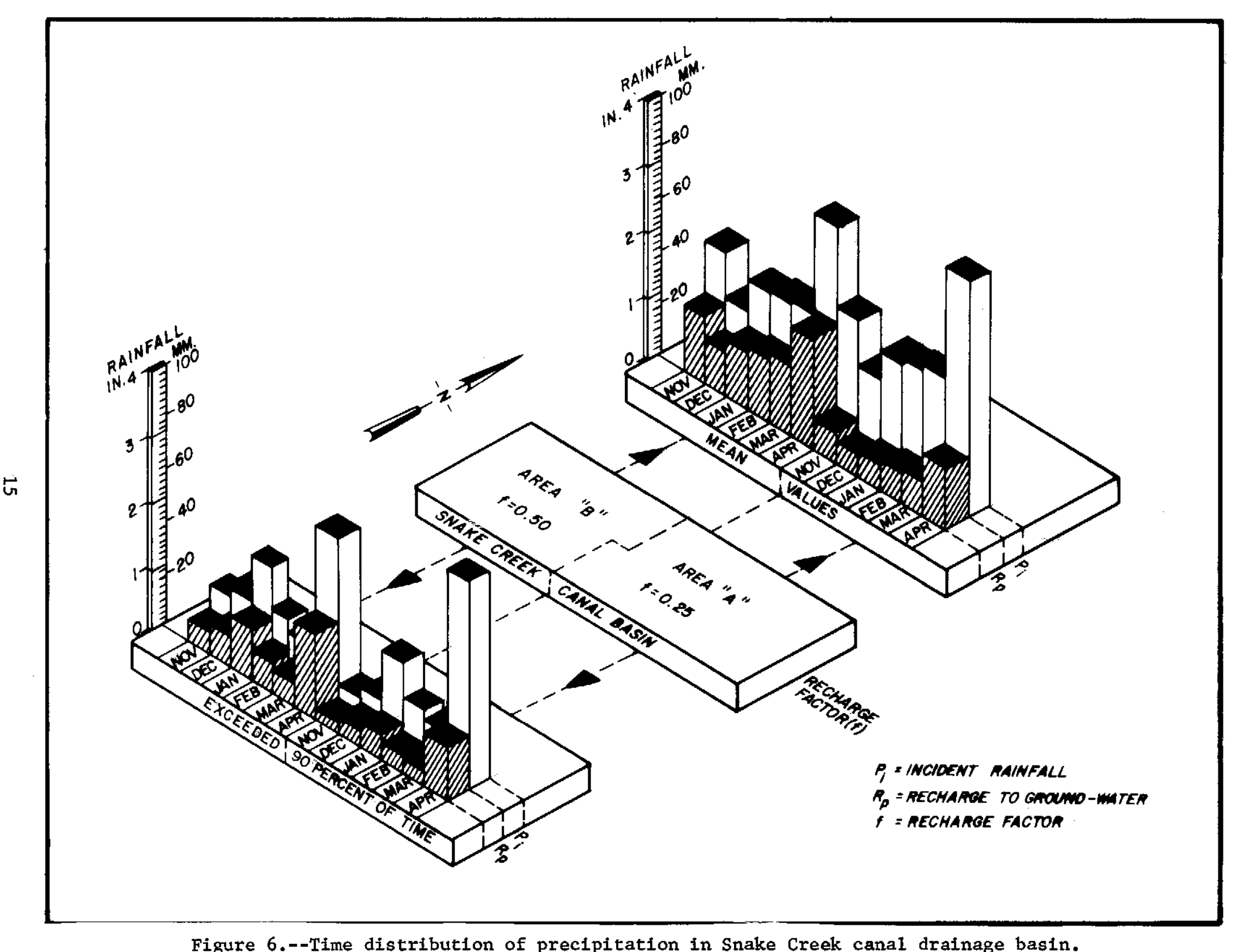


Table 3.--Computed rainfall for analog model simulations from published data at station Pensuco 5-NW, Miami.

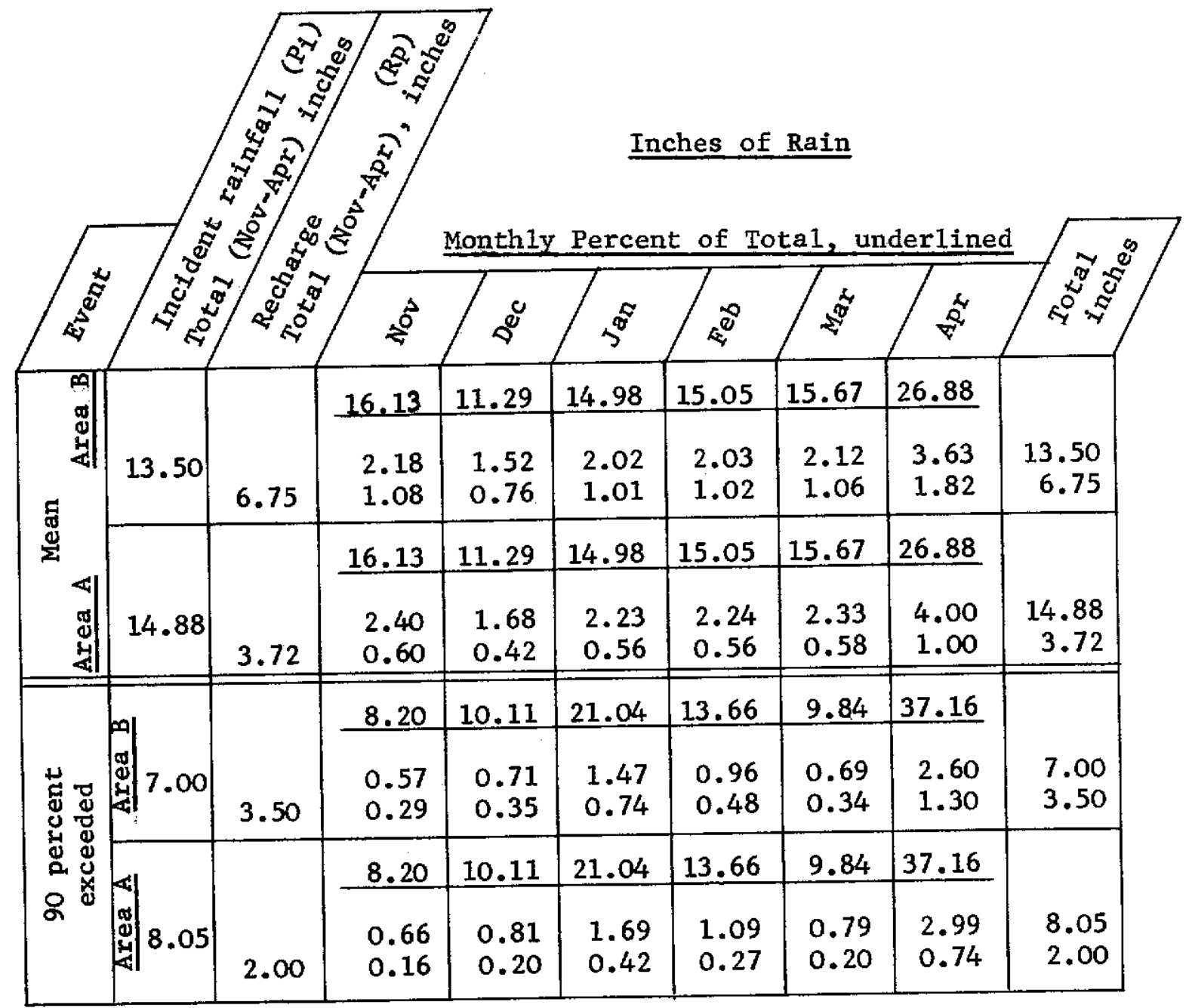


Table 4.--Net recharge (Rp) by area for rainfal1 conditions exceeded 90 percent of the time, secondary control model.

*Area $\mathrm{A}=$ Coastal urban

Recharge in inches

$$
\begin{array}{llllll}
\text { Nov. } & \text { Dec. } & \text { Jan. } & \text { Feb. } & \text { Mar. } & \text { Apr. } \\
0.16 & 0.20 & 0.42 & 0.27 & 0.20 & 0.75 \\
\text { Total for } 6 \text { months }= & 2.00 \mathrm{in.}
\end{array}
$$$$
\text { *Area } \mathrm{B}=\text { Inland undeveloped }
$$

Recharge in inches

$$
\begin{array}{llllll}
\text { Nov. } & \text { Dec. } & \text { Jan. } & \text { Feb. } & \text { Mar. } & \text { Apr. } \\
0.29 & 0.35 & 0.74 & 0.48 & 0.34 & 1.30 \\
& \text { Total for } 6 \text { months }=3.50 \mathrm{in.}
\end{array}
$$

*Areas are shown in figure 3. 
Table 5.--Estimated ground-water withdrawa1 from various pumping centers in the model basin, prorated on Miami well field records for 1970-71.

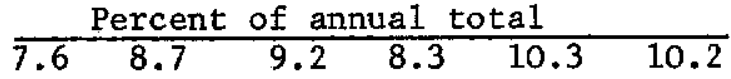
Month Nov. Dec. Jan. Feb. Mar. $\frac{\text { Apr. }}{31}$
Semi- Total Annual annual pumping average total 1970-71 daily rate

\begin{tabular}{|c|c|c|c|c|c|c|c|c|c|}
\hline \multirow{3}{*}{$\begin{array}{l}\text { Rate } \\
\text { Volume }\end{array}$} & \multirow{3}{*}{\multicolumn{2}{|c|}{$\begin{array}{ll} & \text { We11 } \\
8.3 & 9.2 \\
250 & 286\end{array}$}} & \multicolumn{3}{|c|}{ Coordinate $\mathrm{CH}-103$} & & & & \multirow{3}{*}{9.0} \\
\hline & & & 9.7 & 9.7 & 10.9 & 11.2 & & & \\
\hline & & & 302 & 273 & 338 & 335 & 1784 & 3285 & \\
\hline & & & \multicolumn{3}{|c|}{ Coordinate CG-111 } & & & & \multirow{3}{*}{6.8} \\
\hline P.ate & 6.3 & 7.0 & 7.4 & 7.4 & 8.2 & 8.4 & & & \\
\hline \multirow[t]{2}{*}{ Volume } & 188 & 216 & 228 & 206 & 256 & 253 & 1347 & 2482 & \\
\hline & & We11 & \multicolumn{3}{|c|}{ Coordinate CL-119 } & & & & \multirow{4}{*}{11.2} \\
\hline Rate & 10.4 & 11.5 & 12.1 & 12.1 & 13.6 & 13.9 & & & \\
\hline \multirow[t]{2}{*}{ Volume } & 311 & 356 & 376 & 339 & 421 & 416 & 2219 & 4088 & \\
\hline & & We11 & \multicolumn{3}{|c|}{ Coordinate $\mathrm{CN}-115$} & & & & \\
\hline Rate & 2.7 & 3.0 & 3.1 & 3.1 & 3.5 & 3.6 & & & \multirow[t]{3}{*}{2.9} \\
\hline \multirow[t]{2}{*}{ Volume } & 80 & 92 & 97 & 88 & 109 & 108 & 574 & 1059 & \\
\hline & & We11 & \multicolumn{3}{|c|}{ Coordinate CF-116 } & & & & \\
\hline Rate & 2.3 & 2.6 & 2.7 & 2.7 & 3.0 & 3.1 & & & \multirow[t]{2}{*}{2.5} \\
\hline \multirow{2}{*}{ Volume } & 69 & 79 & 84 & 76 & 94 & 93 & 495 & 912 & \\
\hline & & We11 & \multicolumn{3}{|c|}{ Coordinate $\mathrm{CK}-114$} & & & & \multirow{3}{*}{1.8} \\
\hline Rate & 1.7 & 1.8 & 1.9 & 1.9 & 2.2 & 2.2 & & & \\
\hline \multirow{2}{*}{ Volume } & 50 & 57 & 60 & 55 & 68 & 67 & 357 & 657 & \\
\hline & & We11 & \multicolumn{3}{|c|}{ Coordinate $\mathrm{CN}-107$} & & & & \multirow{3}{*}{5.9} \\
\hline Rate & 5.5 & 6.0 & 6.4 & 6.4 & 7.2 & 7.3 & & & \\
\hline \multirow[t]{2}{*}{ Volume } & 164 & 187 & 198 & 179 & 222 & 220 & 1170 & 2154 & \\
\hline & & We11 & \multicolumn{3}{|c|}{ Coordinate BT-110 } & & & & \multirow{3}{*}{0.2} \\
\hline Rate & 0.2 & 0.2 & 0.2 & 0.2 & 0.2 & 0.2 & & & \\
\hline \multirow[t]{2}{*}{ Volume } & 6 & 6 & 7 & 6 & 8 & 7 & 40 & 73 & \\
\hline & & We11 & Coordi & nate $\mathrm{C}$ & $A-104$ & & & & \\
\hline Rate & 1.9 & 2.2 & 2.3 & 2.3 & 2.5 & 2.6 & & & 2.1 \\
\hline Volume & 58 & 67 & 71 & 64 & 79 & 78 & 417 & 767 & \\
\hline & & We11 & Coordi & late $B$ & $Z-119$ & & & & \\
\hline Rate & 0.4 & 0.4 & 0.4 & 0.4 & 0.5 & 0.5 & & & 0.4 \\
\hline Volume & 11 & 13 & 13 & 12 & 15 & 15 & 79 & 146 & \\
\hline & & We11 & Coordi & late C & A-109 & & & & \\
\hline Rate & 4.8 & 5.3 & 5.6 & 5.6 & 6.3 & 6.5 & & & 5.2 \\
\hline Volume & 144 & 165 & 175 & 158 & 195 & 194 & 1031 & 1898 & \\
\hline & & We 11 & Coordi & late $\mathrm{C}$ & $E-120$ & & & & \\
\hline Rate & 2.2 & 2.5 & 2.6 & 2.6 & 2.9 & 3.0 & & & 2.4 \\
\hline Volume & 67 & 76 & 81 & 73 & 90 & 89 & 476 & 876 & \\
\hline Tota 12 & 1398 & 1600 & 1692 & 1529 & 1895 & 1875 & & & \\
\hline 1 Unit & al/ & & & & & & & & \\
\hline 2 Volu & Mga1 & & & & & & & & \\
\hline
\end{tabular}


sumed function throughout the mode1 basin. The ET function in figure 7 is inversely proportional to the depth of the water table below the land surface for depths between $1(0.304 \mathrm{~m})$ and 11.4 feet $(3.47 \mathrm{~m})$, according to the following relationship (Stewart and Mills 1967);

$$
\begin{aligned}
& E T_{x}=3.26(1.10-0.096 x) \text { where } \\
& x=\text { depth below land surface, in } \mathrm{ft} . \\
& \mathrm{ET}_{\mathrm{x}}=\text { Evapotranspiration potential, in inches per month. }
\end{aligned}
$$

This parameter, as a function of depth to water, is graphed in figure 7. The ET potential will range from a maximum of 3.26 inches $(82.8 \mathrm{~mm})$ per month when $x$ is 1 foot or less, to zero when $x$ is greater than $11.4 \mathrm{ft}$ $(3.47 \mathrm{~m})$. The limitations on the ET potential in the model are approximated electronically by current limiting diodes whose electrical properties regulate the flow of current out of the ground-water net. The ET function is applied uniformily over both area A and area B on figure 3 .

\section{Analysis of Simulations}

A reference, or base-level, condition was established by a two-step procedure. First, initial water-level conditions for October, 1972 were established by operating the model with known stress for a 12-month simulation period with no secondary control on Snake Creek Canal and with all other controls closed. Then, from this near steady-state condition the mode 1 was operated for a 6-month simulation period with selected control schemes on Snake Creek canal. Water budgets for each scheme could then be compared to determine isolated effects of Snake Creek controls.

A quantitative comparison was made of the effect of varying the control-gate openings on the net change in the water supply entering and leaving the basin. If both the primary and secondary control structures were closed for the 6 months, the losses due to canal outflow from the basin should be minimized. By comparing alternative operating modes to this condition, the effect of different control operations could be evaluated.

Simulations to test the effect of the secondary control were programed in two sets. One set of results describes analysis for only the primary control in static or dynamic operation, a second set combines both the primary and secondary controls in static or dynamic operation.

Table 6 shows the various model solutions, for base-level conditions and test runs, in the form of water budgets. A11 tests labelled 1 were run from base-level condition 1 (fig. 8) and all tests labelled 2 were run from base-level condition 2 (fig. 9). Stall differences between base level conditions 1 and 2 are the result of running the model on separate occasions but they are assumed equivalent for comparative analysis.

Several of the variables in table 6 are independent since they are programmed with time. Others are dependent and derive their values from 


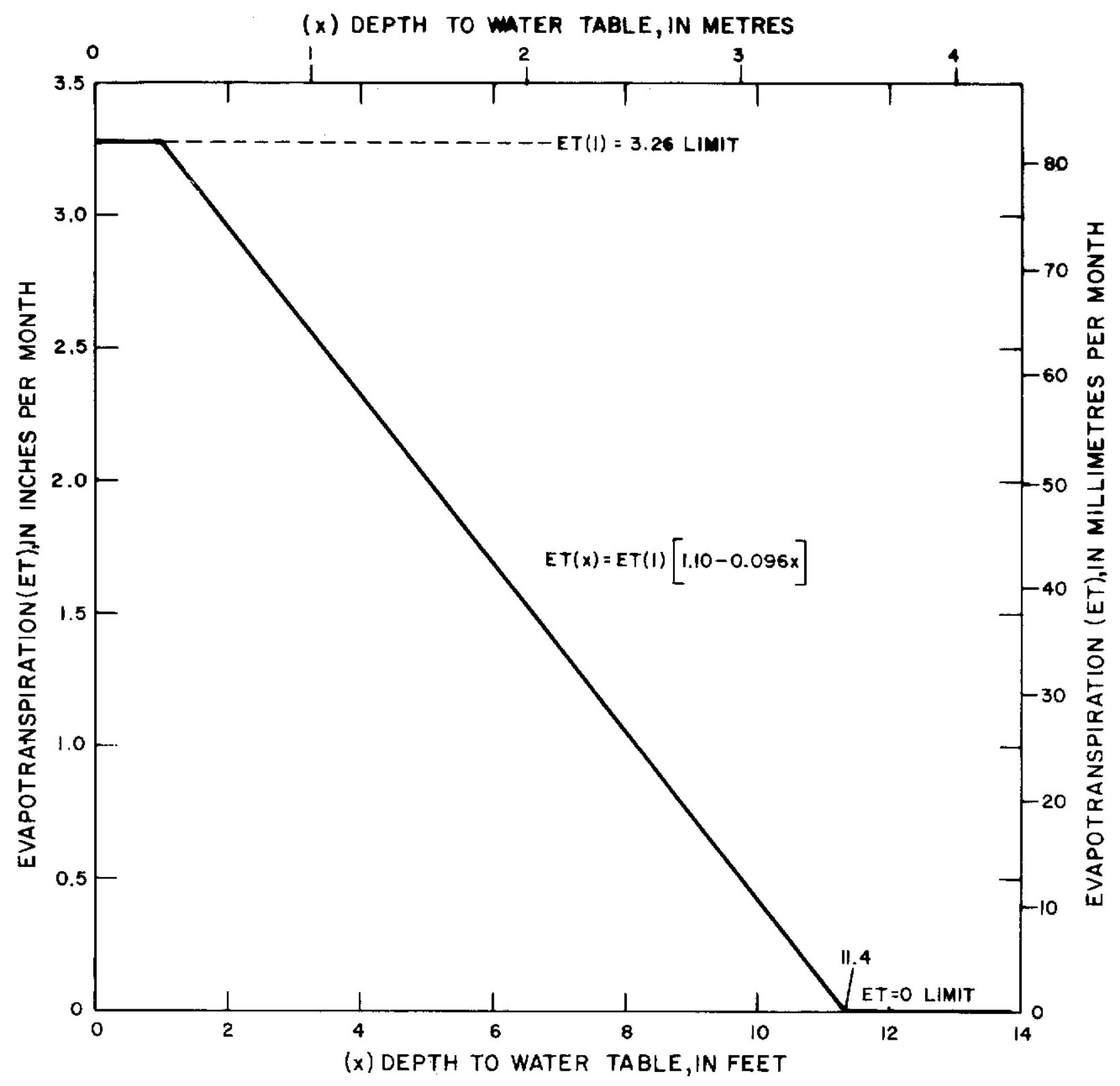

Figure 7.--Relation of evapotranspiration (ET) to water-table depth. 


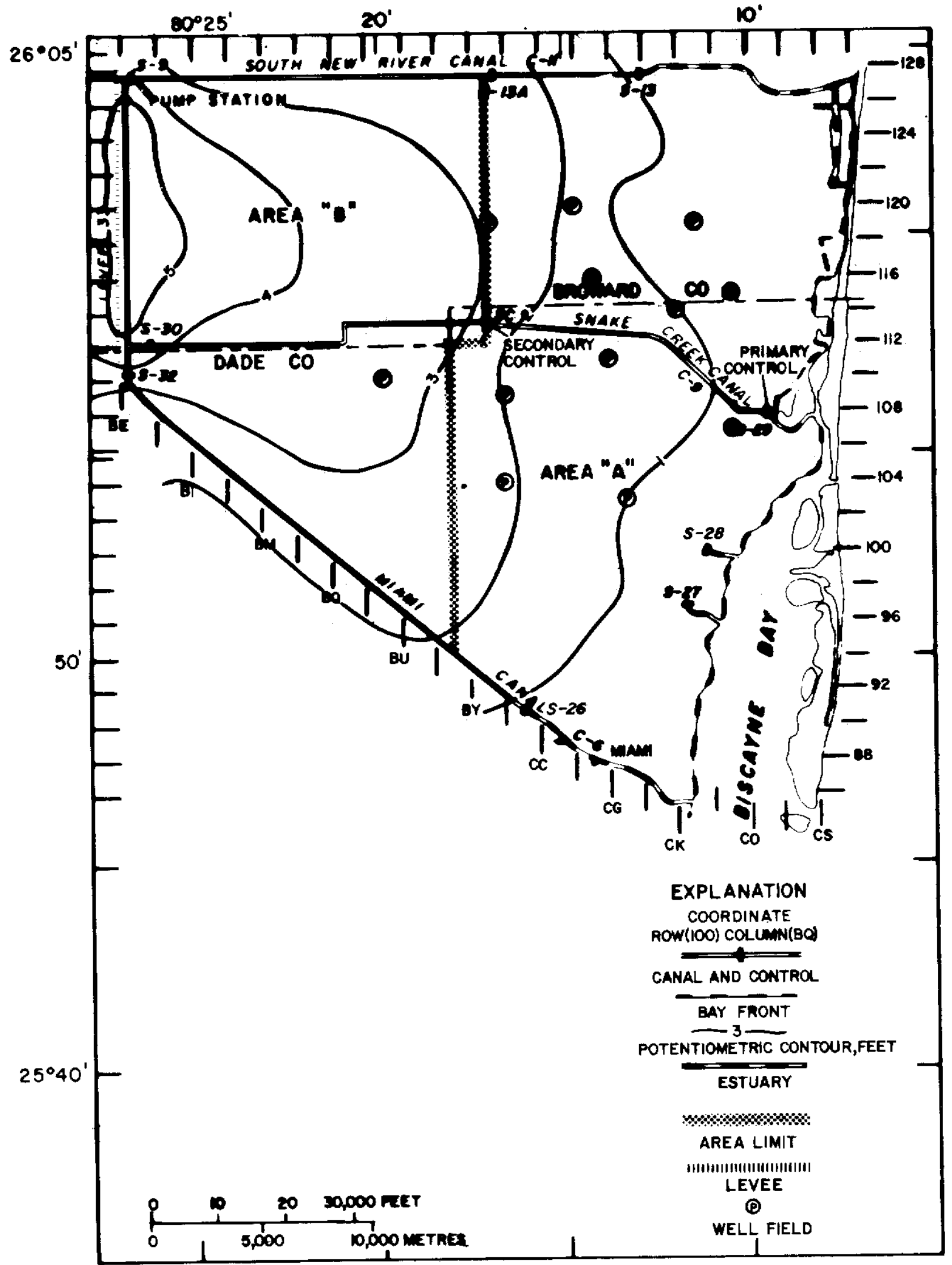

Figure 8.--Secondary control mode1, base level potentiometric surface; condition 1 , run 74-38. 


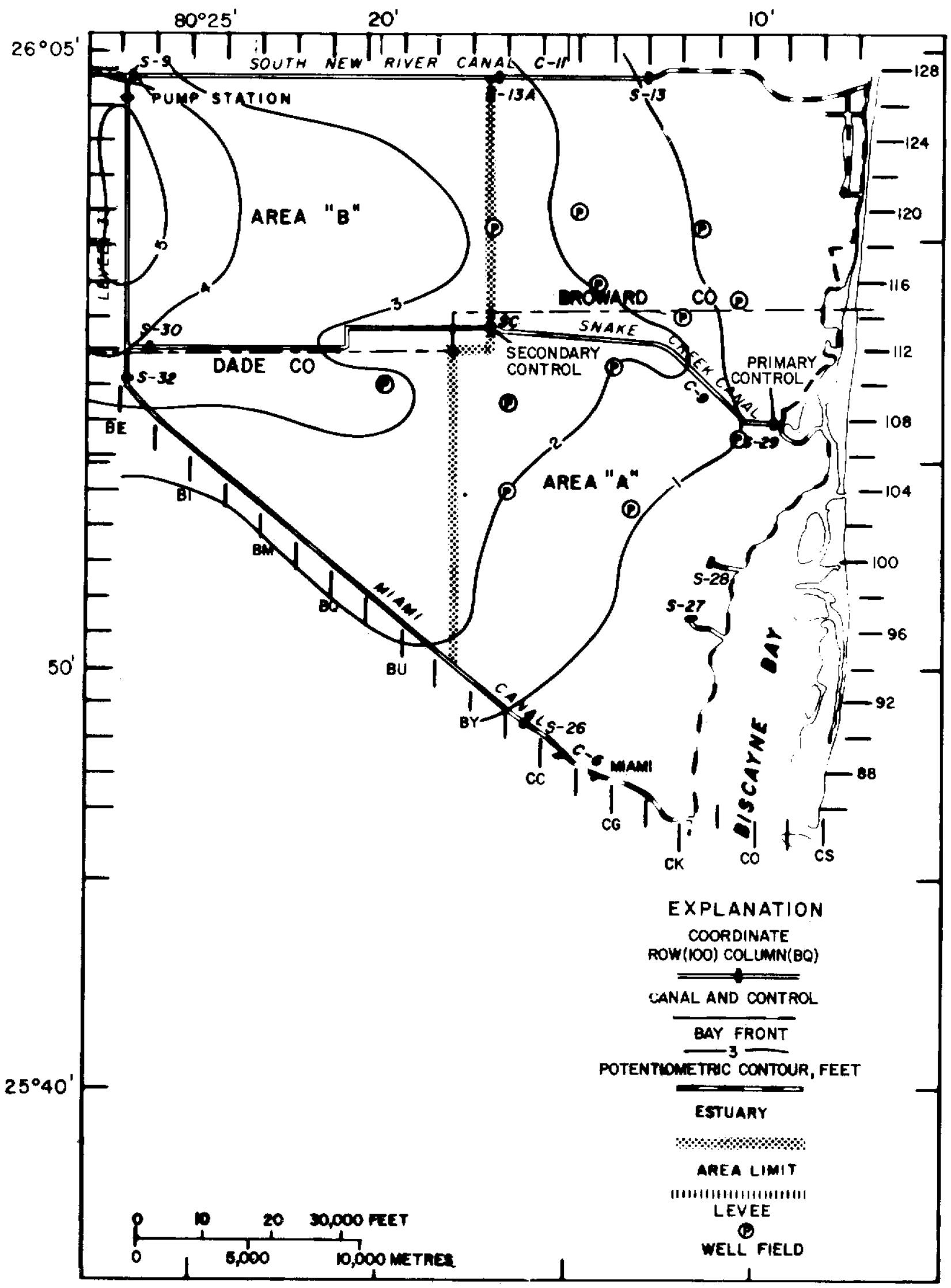

Figure 9.--Secondary control mode1, base leve1 potentiometric surface; condition 2 , run $74-40$. 
the model response. The worst case of hydrologic conditions is shown by analysis group $B$ in table 6 for a model having both the coastal or primary control and the secondary control open 5 ft during the entire 6-month test period. Neither control was subject to any form of operating schedule. Snake Creek Canal flow totalled $78 \times 10^{8}$ and $96 \times 10^{8}$ gal at the end of the respective test periods. Within group B a comparison of analysis 1 and 2 showed the addition of the secondary control structure (B-1) reduced the discharge from the canal by about 19 percent. Some evidence of the reduction of surface-water discharge from the basin is shown in figures 10 and 11 , by arrested development of the ground-water gradient toward the coast. In each analysis group on table 6 , except group $A$, the addition of the secondary control resulted in additional ground-water storage within the basin. A comparison of ground-water storage between analysis group B-1 and $\mathrm{D}-1$ showed that $\mathrm{B}-1$ increased net basin storage about 18 percent. $A$ comparison of results from analysis groups $\mathrm{B}-2$ and $\mathrm{D}-2$ shows that $\mathrm{B}-2$ resulted in about 27 percent more ground water in storage. One reason for the higher percentage of ground water in storage may be the slight variation in the initial conditions that constitute the base for the two analysis groups, but the major cause is the vast reduction in ground-water drainage by the canal. Since evapotranspiration is modeled as a function of the water-table depth a proportionately higher ET loss (22 percent increase) in B-2 from the additional water in storage would be expected.

Discharge of ground water to the bayfront, as noted in table 6 , is actually higher during the group $\mathrm{C}$ and $\mathrm{D}$ analysis which have operating control structures. It is therefore concluded that operating the control or controls will help to retard saltwater intrusion on the bayfront boundary.

A considerable change in Snake Creek Canal discharge was measured between the analysis groups $\mathrm{C}$ and $\mathrm{D}$ wherein the structures are controlled by water stage and the analysis group $B$ with structures continually open. Only minor variations result from changes in the amount of the gate opening. Analysis group D-1, where structures are open and closed according to water stage in the canal, indicates that canal discharge would decrease 100 percent from that which occurred in analysis group B-1. With the primary controloperating alone (group D-2) the canal discharge decreased by 90 percent in comparison to group $\mathrm{B}-1$, therefore, operation of the secondary control accounts for only 10 percent of the canal flow reduction. Comparison of the categories in group $c$, having only $1 \mathrm{ft}(0.3 \mathrm{~m})$ gate opening, with group $\mathrm{D}$, having $5 \mathrm{ft}(1.5 \mathrm{~m})$ gate opening, showed no change in canal discharge. The model is apparently insensitive to the amount of contro1 opening.

Major changes in ground-water storage were expected to occur in these analyses. Recharge and canal levels of the model corresponded to a condition of deficiency in precipitation. Other deficiencies occurred in the inflow from both Miami Canal and the Conservation Area. The deficiency in rainfall was offset in part by a reduction in ET losses resulting from lowering of the water table. Figures 10-17 show the areal changes in the water table for all of the model analyses of table 6. 


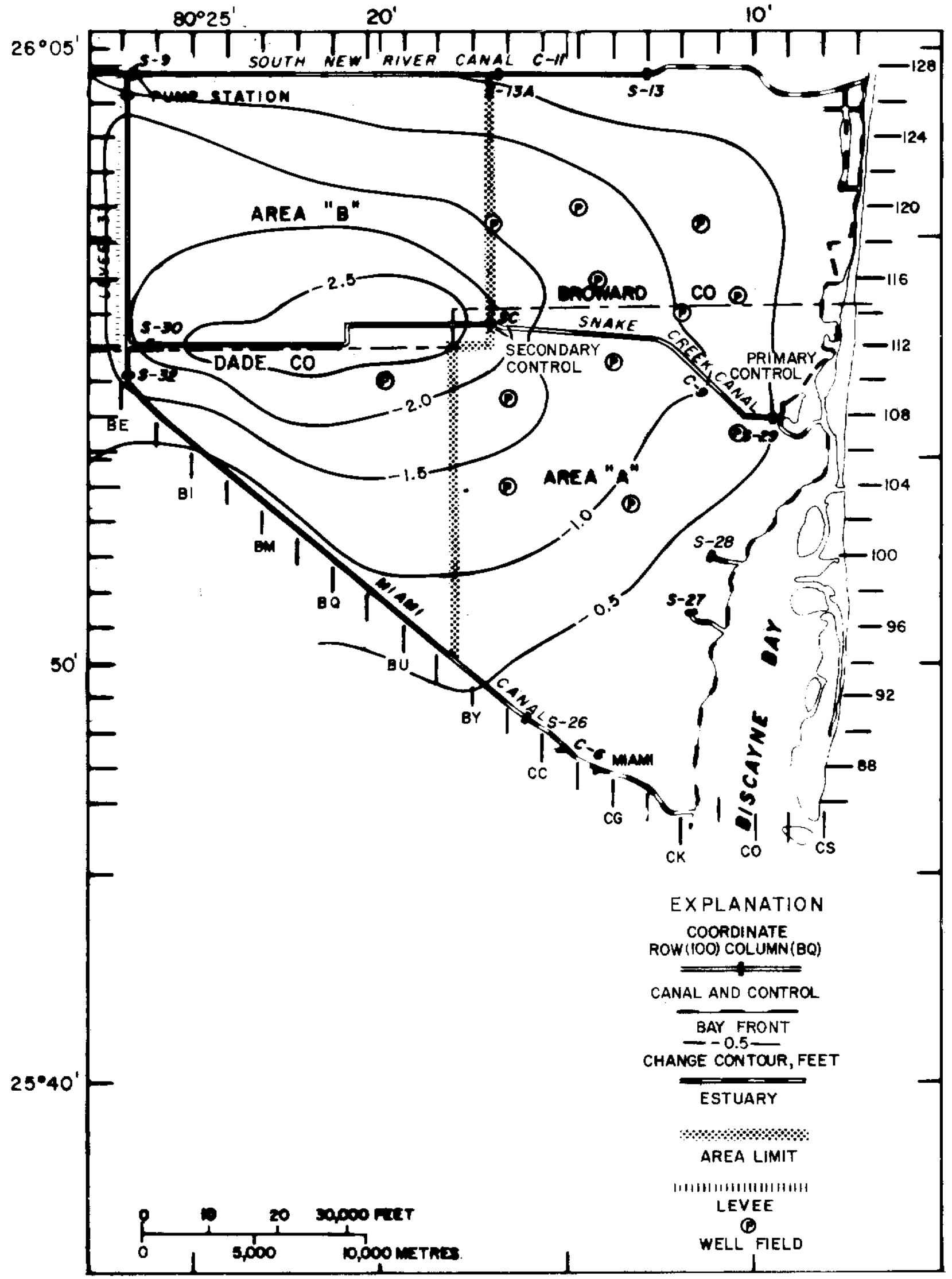

Figure 10.--Secondary control model, 6-month change from base level condition; model group $B-1$, run $74-43$. 


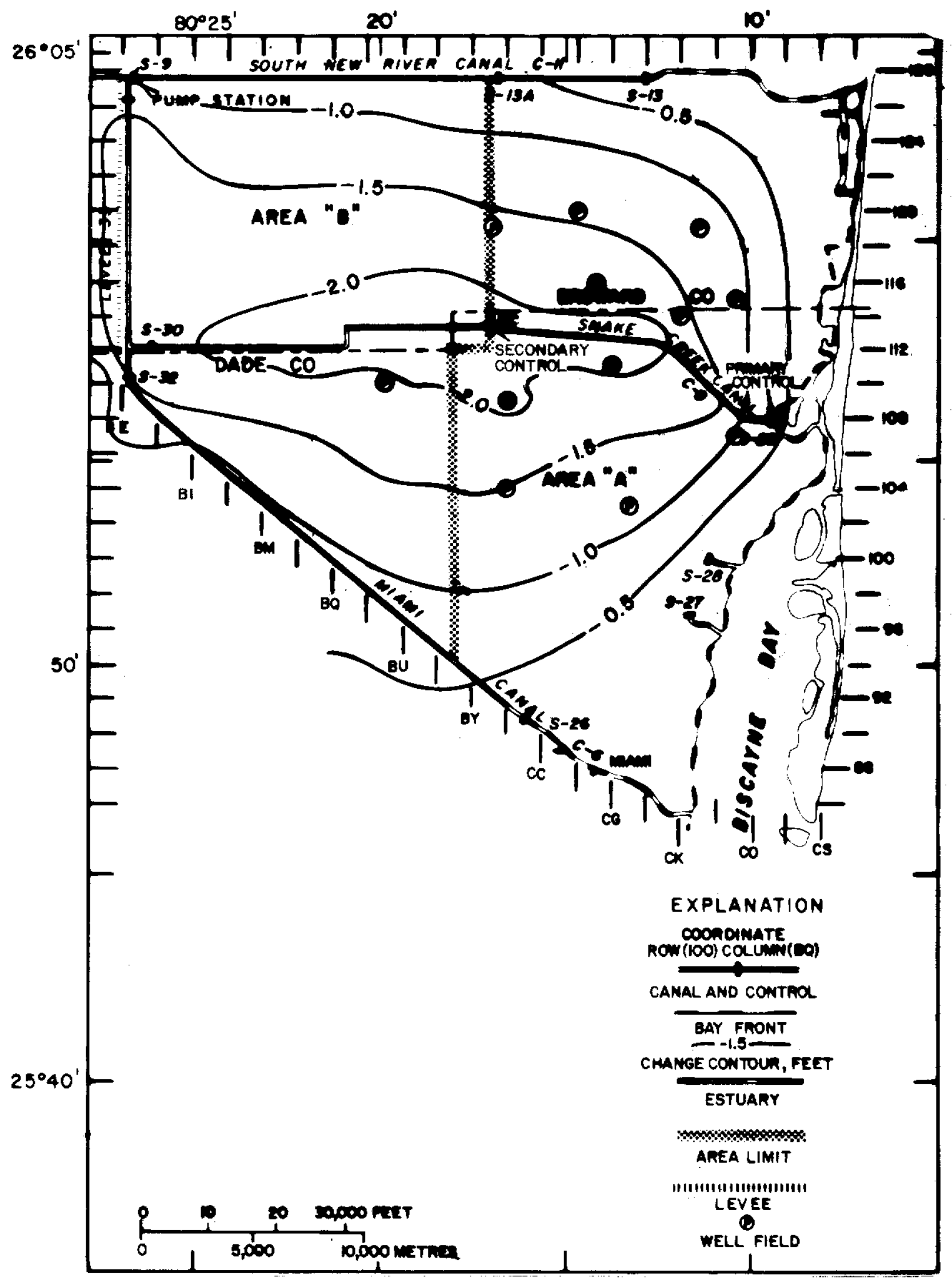

Figure 11.--Secondary control mode1, 6-month change from base level condition; mode1 group B-2, run 74-42. 


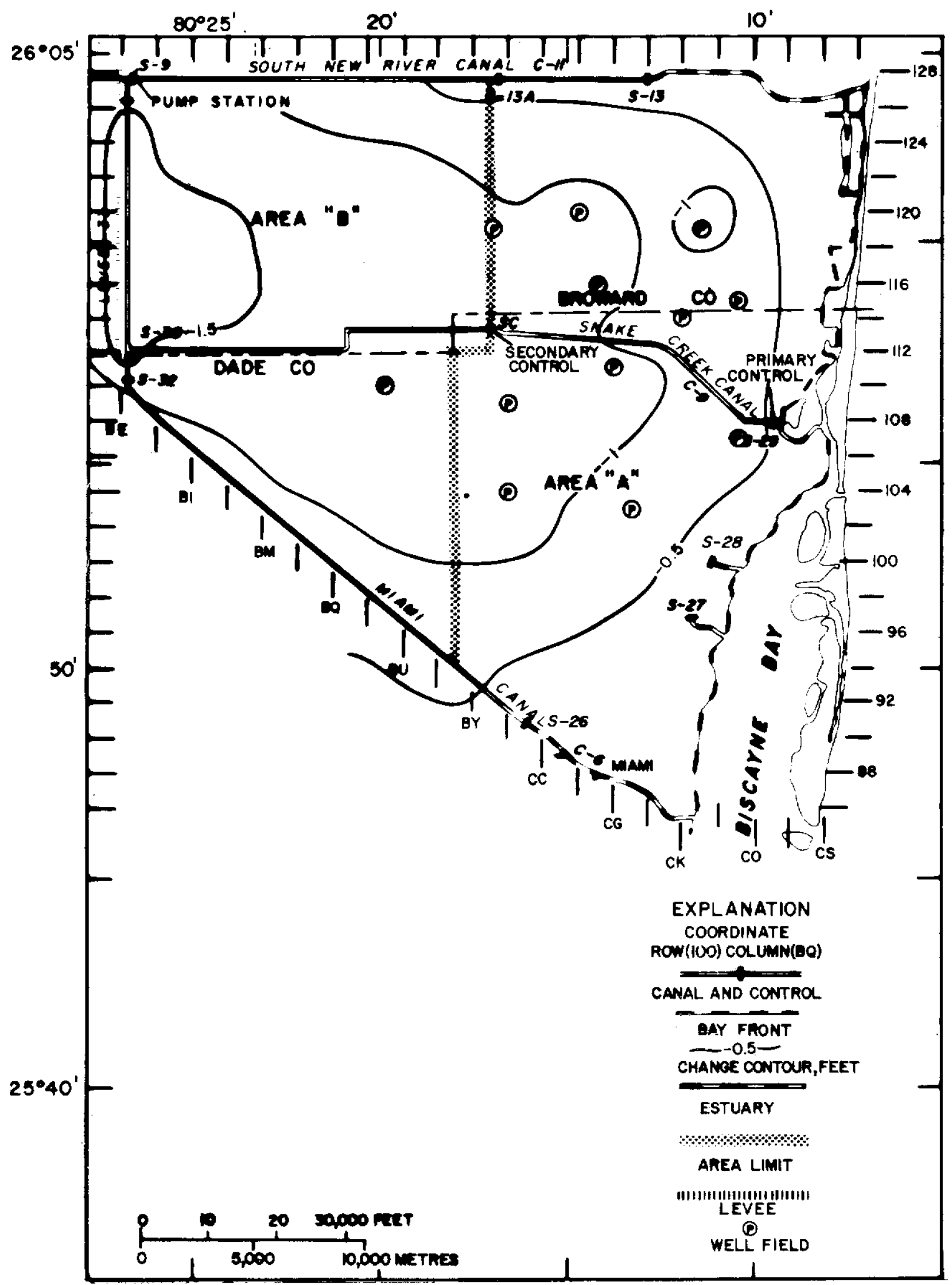

Figure 12..-Secondary control mode1, 6-month change from base leve1 condition; model group A-1, run 74-39. 


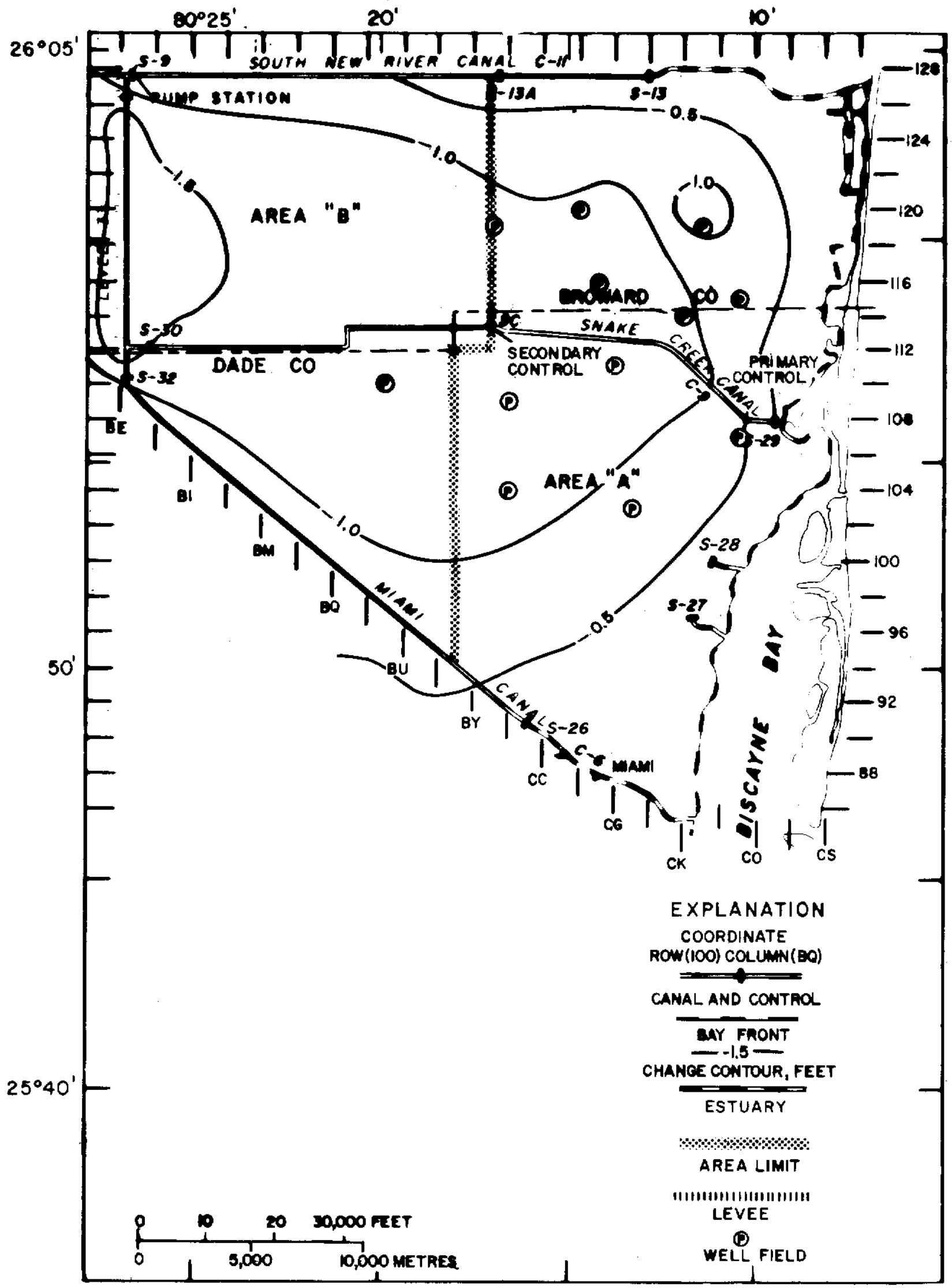

Figure 13.--Secondary control model, 6-month change from base leve1 condition; model group $A-2$, run $74-41$. 


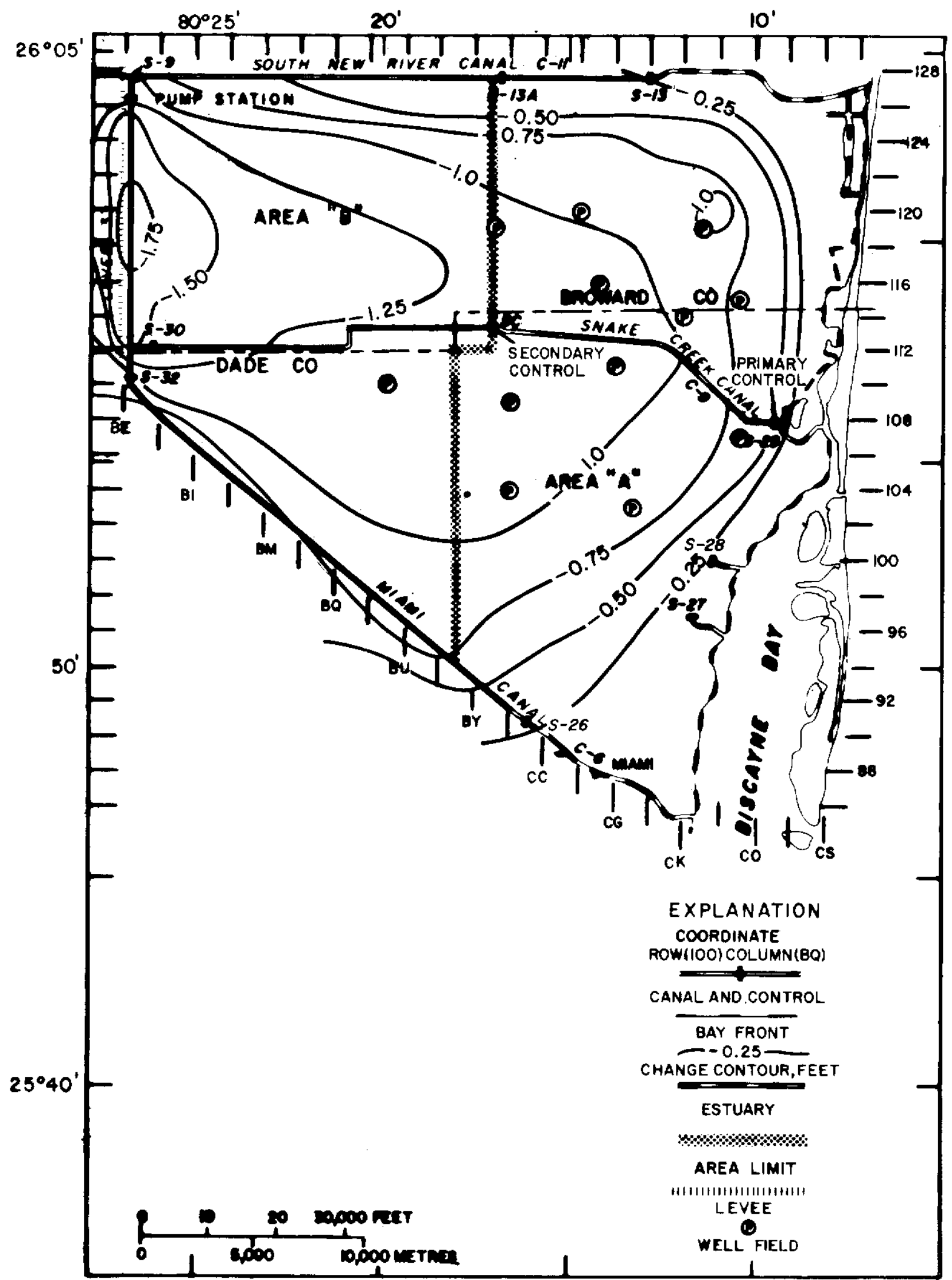

Figure 14.--Secondary contro1 mode1, 6-month change from base leve1 condition; mode1 group C-1, run 74-44. 


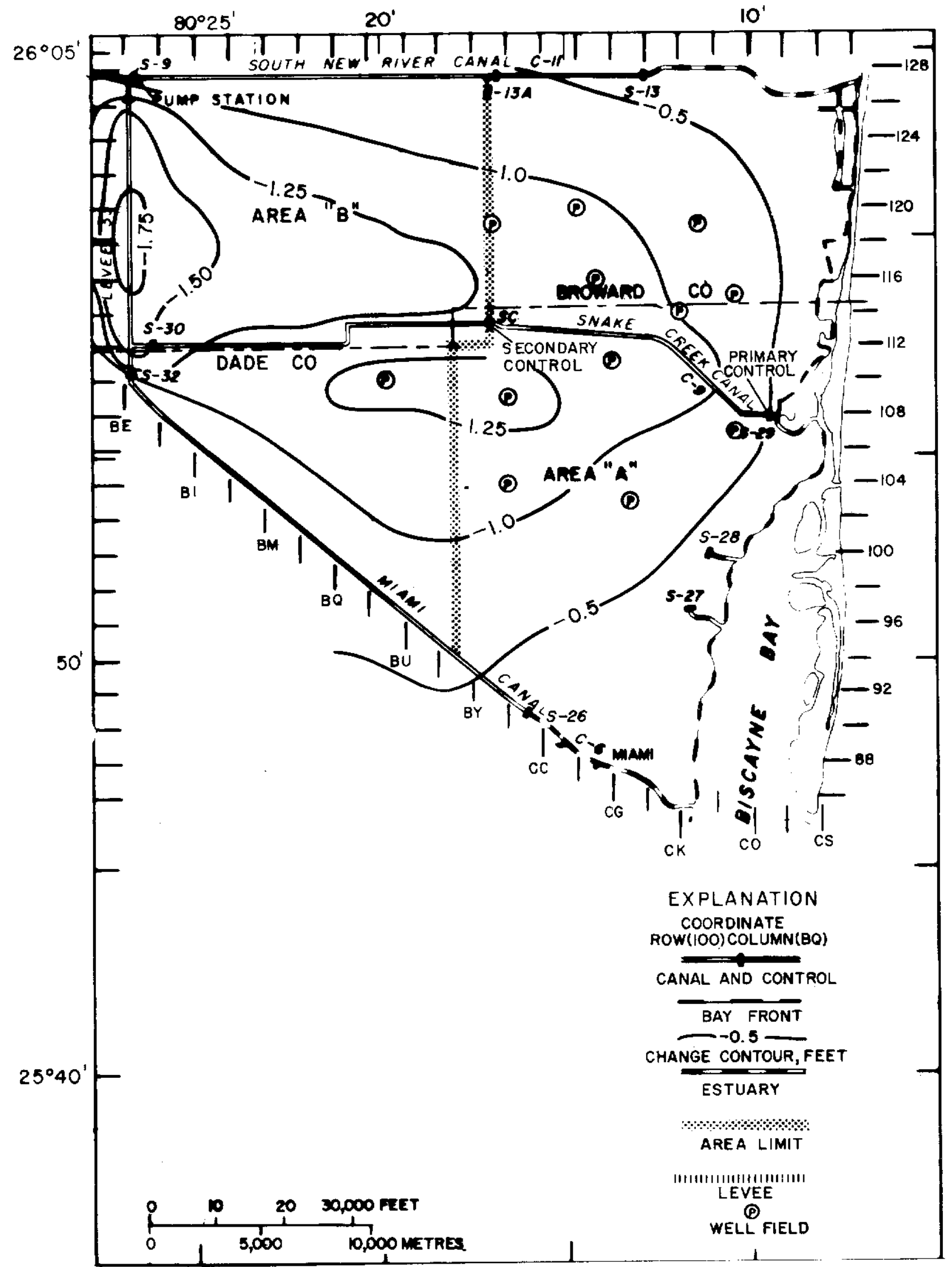

Figure 15.--Secondary control model, 6-month change from base leve1 condition; model group C-2, run 74-46. 


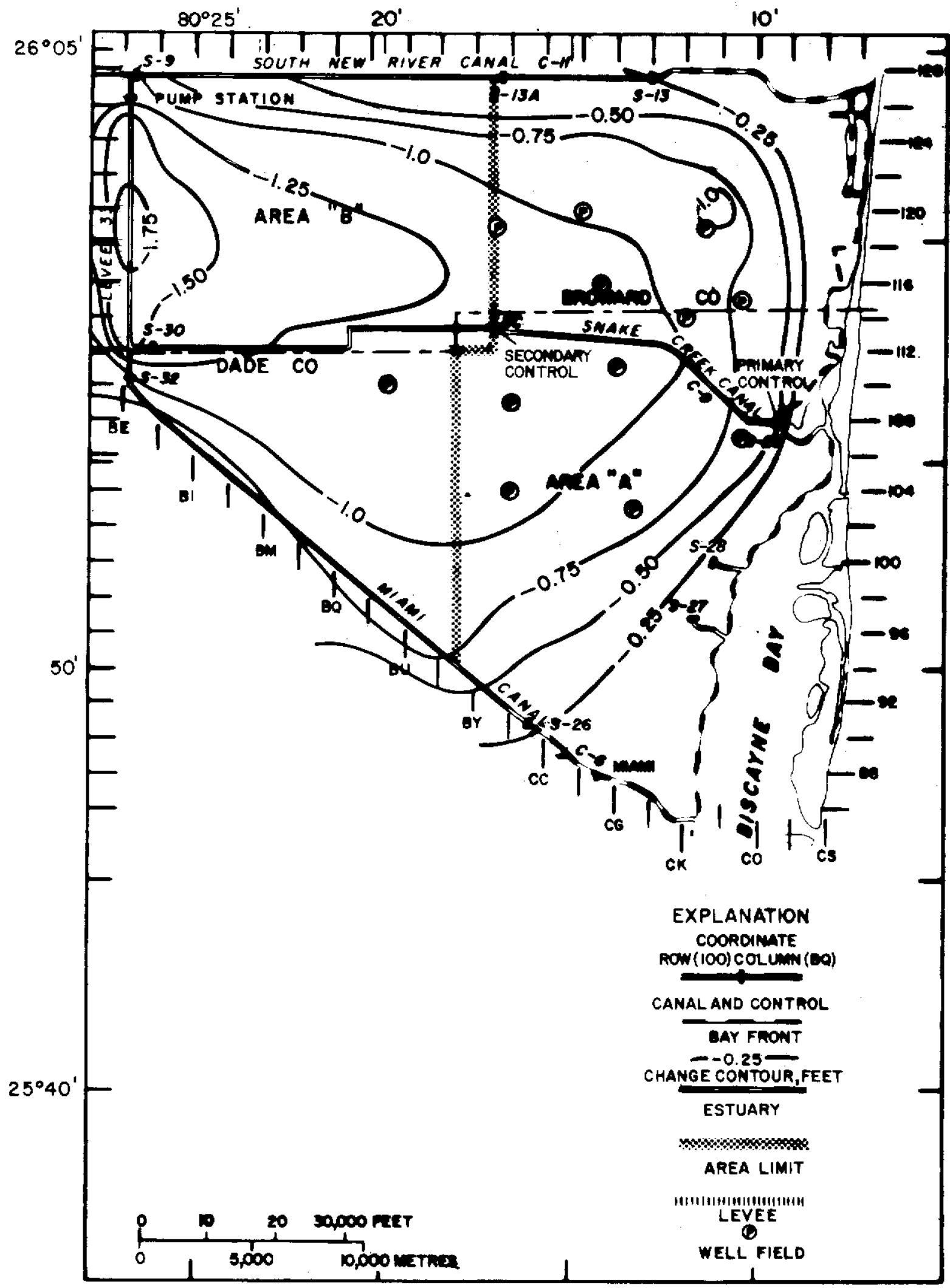

Figure 16.--Secondary control madel, 6-month change from base level condition; model group D-1, run $74-45$. 


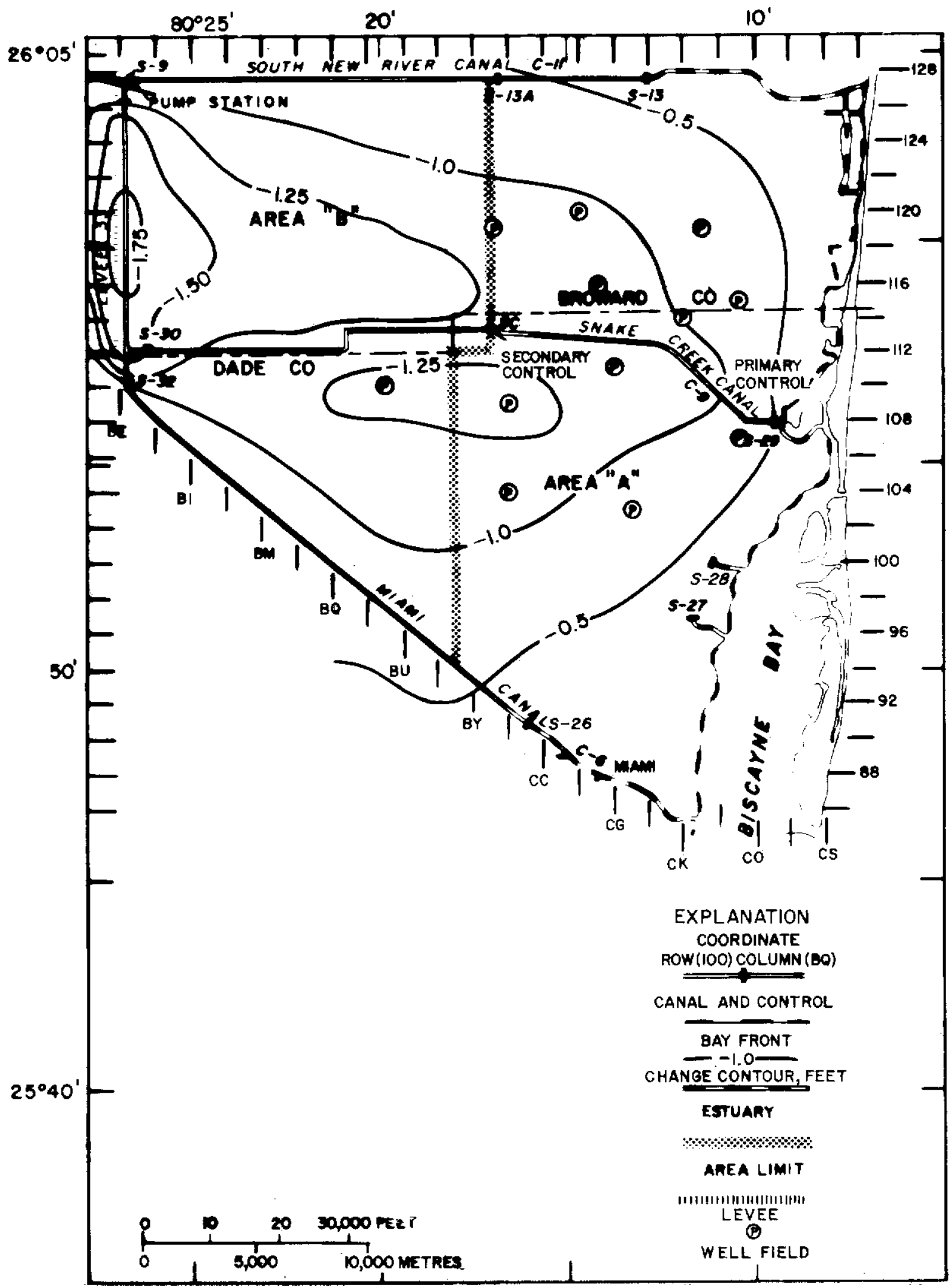

Figure 17.--Secondary control model, 6-month change from base level condition; mode1 group D-2, run 74-47. 
Several favorable results were anticipated as a result of the installation and operation of the control structures. The most beneficial, a reduction of net water loss from the system, would be nullified by excessive inflow of saltwater from the bayfront. Optimum conditions would result from a reduction in ET losses, continued canal discharge to the bayfront, and minimizing depletion of ground-water storage.

It must be recognized, however, that the changes imposed by the secondary control are minimal. As modeled, the primary and secondary controls have instantaneous interaction and form complementary functions in accordance with the operating schedules in table 2. Thus a minimal effect of the secondary control structure is revealed by these model analyses. The results tend to minimize the real conditions that would result if a secondary structure were installed on Snake Creek canal. If the model were designed to simulate canal conveyance losses associated with surface-water flow and changes of storage within the canal, the impact of the secondary control might be greater.

\section{Summary}

The concept of using a secondary control structure in canals as a method of water conservation was tested using the Biscayne aquifer electric analog mode1. In general, the model analyses showed minor changes in the hydrologic conditions of the basin in response to the addition of a secondary control structure. The effects that were observed are mainly due to the operation of primary coastal control structures and to the other modeling parameters. Even with the limited sensitivity shown by the mode1, a secondary control structure can be a viable means to optimize water conservation provided the operating rules are in harmony with the primary coastal control structure.

The analyses revealed that the dominant control on the hydrologic system is the coastal control structure. The criterion of trying so maintain a positive $2.5-\mathrm{ft}(0.76-\mathrm{m})$ head above the primary structure resulted in the structure being closed much of the time. For periods when the structure is open $5 \mathrm{ft}$ $(1.5 \mathrm{~m})$, larger quantities of water are discharged and the canal head falls rapidly. When the gate is open $1 \mathrm{ft}(0.3 \mathrm{~m})$, smaller quantities are discharged and a longer time is required to lower the canal head to $2.5 \mathrm{ft}(0.76 \mathrm{~m})$. In either case, however, the time that the gate is open is small in comparison to the 6-month computational period. Accordingly, the volume of flow past the primary structure is large when the gate is not controlled (groups B-1, B-2), and much smaller when the gate is controlled (groups D-1, D-2).

\section{PROPOSAL FOR FORWARD PUMPING}

Forward pumping is a proposed water-management scheme whereby water is pumped from the Biscayne aquifer in inland areas of little or no withdrawals, and moved eastward to areas of heavy withdrawals during the November to April dry season. Conveyance will be through existing canals or through facilities to be constructed. This would provide additional infiltration to the aquifer in the vicinity of well fields along the coast and retard the migration of saltwater into the aquifer. The lowering of the water table in the interior will result in salvage of water now lost to evapotranspiration, and provide additional underground storage space to be filled during the ensuing wet season. 


\section{Mode1 Design}

The forward pumping scheme was analyzed on the existing Biscayne aquifer electrical analog model (Appe1, 1973) using four test sites remote from areas of heavy ground-water withdrawals (fig. 2). Site AA is east of Levee 30 and north of the Tamiami Canal. Sites A, B and $C$ are west and north of site $\mathrm{AA}$ in Conservation Area 3B. The test areas, $\mathrm{AA}$, $A, B$, and $C$, were selected on the basis of boundary conditions, mainly the number and proximity of canals.

To facilitate comparison of model simulations, a standard sampling area of $225 \mathrm{mi}^{2}\left(583 \mathrm{~km}^{2}\right.$ ) (fig. 18) was established surrounding each forward-pumping test site (fig. 2).

The number and location of the forward pumping wells within the test areas were chosen to create the maximum ground-water storage change. Pumping at three separate rates was programed at each of three locations in area $\mathrm{AA}$; one analysis was made with the internal canals simulated, and one was without the canals. Pumping at two separate rates was programed at sites $A, B$, and $C$. In each of these test sites, pumping was simulated at three or four modes simultaneously. A summary of the forward pumping simulations is given in Table 7 .

The analog model was programed to establish the following conditions:

1. Initial water-table elevations approximated the average october conditions defined by Hul1 and Wimberly (1972).

2. Rainfall during the period of simulation (November to Apri1) was that exceeded 90 percent of the time (Benson and Gardner, 1974). This rainfall was reduced in volume by the estimated volume of direct overland runoff resulting from rainfall to obtain the quantity of recharge to the aquifer. The recharge to the model is shown in table $8, A$.

3. Canal water levels for certain canals were maintalned to approximate average monthly levels during the 1970-71 dry season. These levels are shown in table 8,8 .

4. Withdrawals of ground water for municipal supply are varied with time. The magnitude and variation of pumping at these centers is shown in table 8,C. Locations are shown on figure 28.

5. Evapotranspiration is a function of the depth to water below land surface $(x)$. Thus evapotranspiration varies from 3.26 inches $(82.8 \mathrm{~mm})$ per month when $x$ is $1 \mathrm{ft}(0.3 \mathrm{~m})$ or less to zero when $x$ is $11.4 \mathrm{ft}$ $(3.48 \mathrm{~m})$ or more as shown in figure 7 . 


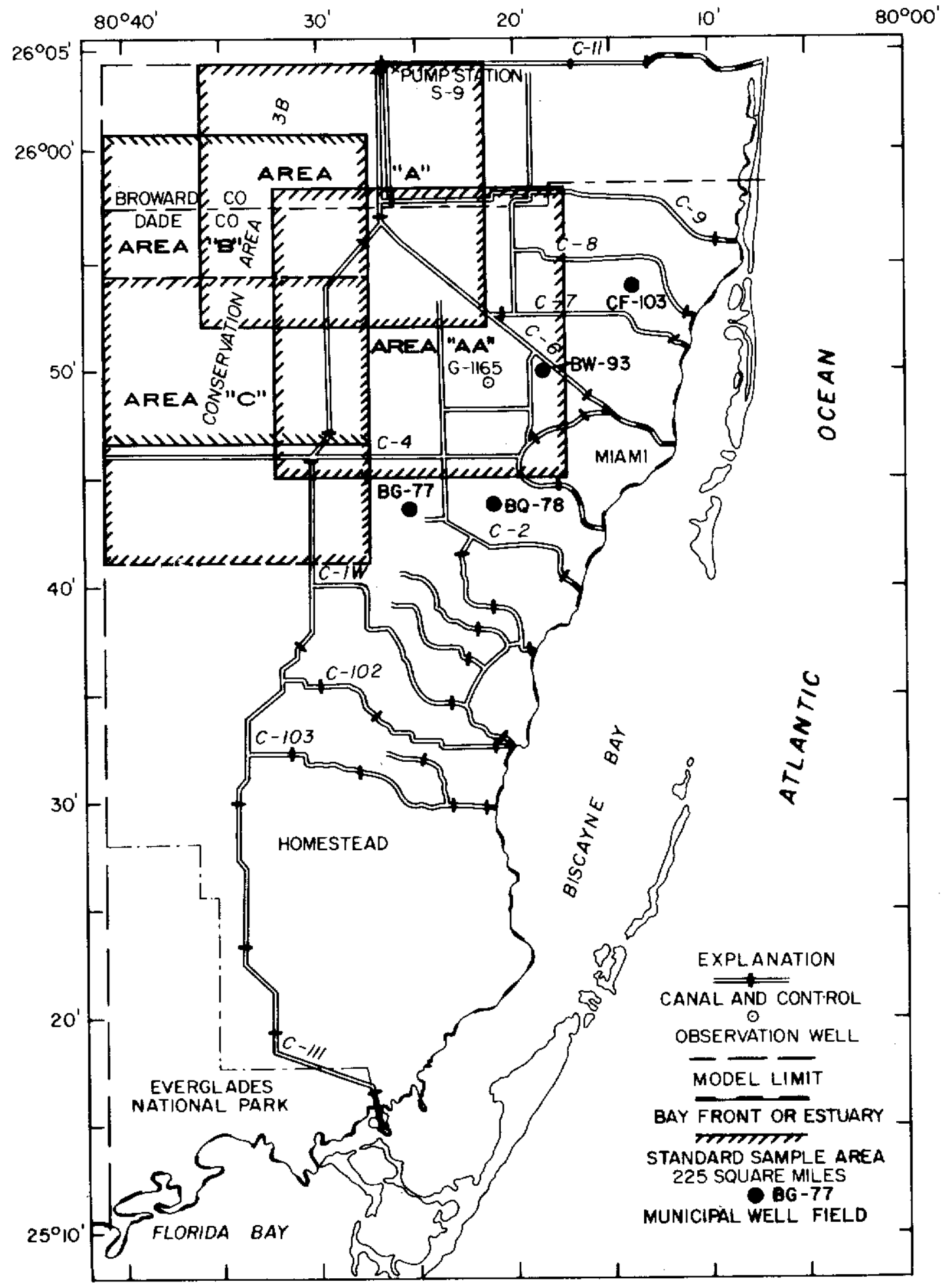

Figure F8.--Forward pumping sample areas on analog model. 
Table 7.--Summary of forward pumping simulations.

\begin{tabular}{|c|c|}
\hline $\begin{array}{l}\text { Test } \\
\text { areas }\end{array}$ & $\begin{array}{c}\text { Simulation } \\
\text { number }\end{array}$ \\
\hline $\mathrm{AA}$ & $74-3$ \\
\hline $\mathrm{AA}$ & 4 \\
\hline $\mathrm{AA}$ & 5 \\
\hline $\mathrm{AA}$ & $6 *$ \\
\hline $\mathrm{AA}$ & $7 *$ \\
\hline $\mathrm{AA}$ & $8 *$ \\
\hline $\mathrm{AA}$ & 9 \\
\hline $\mathrm{AA}$ & $10 *$ \\
\hline $\mathrm{AA}$ & II \\
\hline $\mathrm{AA}$ & $12 *$ \\
\hline $\mathrm{AA}$ & 13 \\
\hline $\mathrm{AA}$ & $14 *$ \\
\hline $\mathrm{AA}$ & 15 \\
\hline $\mathrm{AA}$ & $16 *$ \\
\hline $\mathrm{AA}$ & 17 \\
\hline $\mathrm{AA}$ & $18 *$ \\
\hline $\mathrm{AA}$ & 19 \\
\hline $\mathrm{AA}$ & $20 *$ \\
\hline A & 28 \\
\hline A & 29 \\
\hline B & 30 \\
\hline B & 31 \\
\hline C & 32 \\
\hline $\mathrm{C}$ & $74-33$ \\
\hline
\end{tabular}

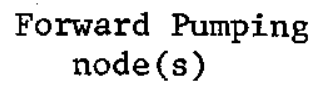

118-BC, 114-AY, 112-BA

$118-\mathrm{BC}, 114-\mathrm{AY}, 112-\mathrm{BA}$

98-AK, 102-AO, 106-AQ, 110-AS

98-AK, 102-AO, 106-AQ, 110-AS

90-AK, 90-AQ, 90-AW

90-AK, 90-AQ, 90-AW
Tota1

additional

storage

(Mga1)

Additional storage.

$\begin{array}{ccc}\text { rate } & \text { volume } & \text { storage } \\ (\mathrm{Mga1} / \mathrm{d}) & \text { (Mgal) } & \text { (Mga1) }\end{array}$

(Percent)

$\begin{array}{rrr}120 & 21,600 & 2,300 \\ 80 & 14,000 & 1,500 \\ 40 & 7,400 & 600 \\ 120 & 21,600 & 4,000 \\ 80 & 14,000 & 2,500 \\ 40 & 7,200 & 1,100 \\ 40 & 7,200 & 900 \\ 40 & 7,200 & 800 \\ 80 & 14,200 & 1,800 \\ 80 & 14,200 & 2,100 \\ 120 & 22,000 & 3,400 \\ 120 & 22,000 & 3,900 \\ 120 & 22,000 & 3,300 \\ 120 & 22,000 & 4,300 \\ 80 & 14,400 & 2,100 \\ 80 & 14,400 & 2,500 \\ 40 & 7,100 & 900 \\ 40 & 7,100 & 900 \\ & & \\ 210 & 37,600 & 13,200 \\ 120 & 22,000 & 7,600 \\ & & \\ 210 & 37,000 & 20,200 \\ 120 & 21,600 & 11,400 \\ 210 & 38,000 & 11,700 \\ 120 & 21,600 & 6,400\end{array}$

10.6

10.7

8.1

18.5

17.9

15.3

12.5

11.1

12.7

14.8

15.5

17.7

15.0

19.5

14.6

17.4

12.7

12.7

34.6

33.6

53.5

51.9

30.8

29.6

*Forward pumping simulation in area AA without internal canals. 
Table 8.--Programmed data to forward pumping model.

A. *Recharge $\left(R_{p}\right)$ exceeded 90 percent of the time:

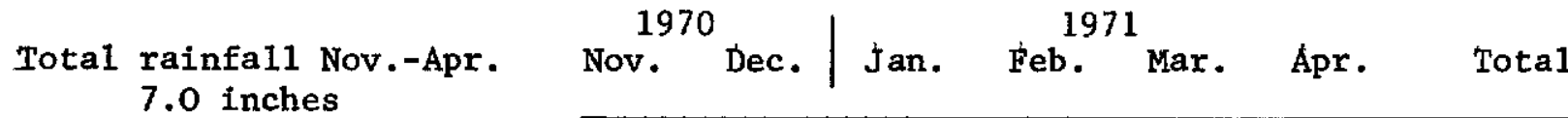

$\begin{array}{llllllll}\text { Weighting Coeff. (percent) } & 8.20 & 10.11 & 21.04 & 13.66 & 9.84 & 37.16 & 100\end{array}$

$\begin{array}{llllllll}\text { Recharge (inches) } & 0.29 & 0.35 & 0.74 & 0.48 & 0.34 & 1.30 & 3.50\end{array}$

*Same as for Secondary Control study.

B. Water levels in feet above sea level:

\begin{tabular}{l|ll}
1970 & & \\
Nov. & Dec. & Jan. Feb. Mar. Apr.
\end{tabular}

Miami Canal C-6

$\begin{array}{llllll}2.48 & 2.60 & 2.55 & 2.50 & 2.10 & 1.85\end{array}$

Tamiami Cana1 C-4

$\begin{array}{llllll}4.00 & 3.70 & 3.25 & 3.00 & 2.55 & 2.10\end{array}$

Levee 30 Cana1

$\begin{array}{llllll}7.16 & 6.66 & 6.16 & 5.66 & 5.16 & 4.66\end{array}$

C. Pumping in million gallons per day

Pumping Node

\begin{tabular}{l|ll}
\multicolumn{2}{|c|}{1970 Nov. } & \multicolumn{2}{|c}{ Dec. } & Jan. Feb. Mar. Apr.
\end{tabular}

BG-77

7.75

8.25

8.25

8.25

$8.75 \quad 9.25$

BQ -78

62

66

66

66

70

74

BW-93

77.

82.5

$82.5 \quad 82.5$

$87.5 \quad 92.5$

CF-103

7.75

8.25

8.25

8.25

$8.75 \quad 9.25$ 
The October hydrologic conditions were set in the model and the model was operated through the November-April period to verify the model by reproducing hydrologic conditions before simulation of the forward pumping scheme. This was done for each of 4 test sites in the model. Forward pumping simulations were then conducted for each of 24 forward pumping configurations.

\section{Analysis of Simulations}

During the dry season water levels in inland areas of the Biscayne aquifer normally decline steadily except for short-term rises caused by 19 unseasonal rainfall as shown by the hydrograph of well G 1165 (fig. 19A) in test site AA. Simulated hydrologic conditions show a similar decline of water levels on fig. 19B but without the irregularities. The decline in simulated water levels is accelerated when forward pumping simulations are imposed on the model (fig. 19C).

The water budget summarized in table 9 provides a mass balance for each model solution. For example, accompanying the accelerated decline induced by the forward pumping simulations is a corresponding reduction in the rate of evapotranspiration losses in the affected area, and an increase in storage space in the aquifer to be filled during the next wet season. The cause and effect relations are apparent.

The change in electrical potential (equivalent to water-leve1 change) after 6 months, for both the nonpumping and the forward pumping simulations was recorded at about half the nodes in the standard sample area. The water levels for the forward pumping simulations were substracted from the water levels for the appropriate nonpumping simulation to get a net water-level change, $\Delta \mathrm{hD}$, (fig. 20). This head change, attributable solely to forward pumping, was then computed by interpolation for all the remaining nodes in the standard sampling area. The head changes for each simulation were arranged in ascending order, grouped into $30 \mathrm{classes,} \mathrm{and}$ their relative frequency of occurrence in the standard sample area was computed. The resulting values were plotted on graphs of which figures 21-25 are typical examples. The graphs provide a quick assessment of the relative effectiveness of the different forward-pumping simulation arrangements.

The use of the standard sample area improves the comparative appraisal of changes in ground-water storage shown in Table 9 with those in Table 7. For example in figure 21, $\Delta \mathrm{h}$ for forward pumping simulation $74-3,55$ percent of the standard sample area AA had a net drawdown in water level of 0.1 foot $(0.25 \mathrm{~m})$ or less. In figure 24 , forward pumping simulation 74-31, only 15 percent of the standard sample area $B$ had a net drawdown of 0.1 foot $(0.25 \mathrm{~m})$ or less, indicating a much more effective simulation from a water-management standpoint when considering only storage space created. The pumping rate for both simulations was $120 \mathrm{Mga} / \mathrm{d}$ $\left(5.26 \mathrm{~m}^{3} / \mathrm{s}\right)$. 


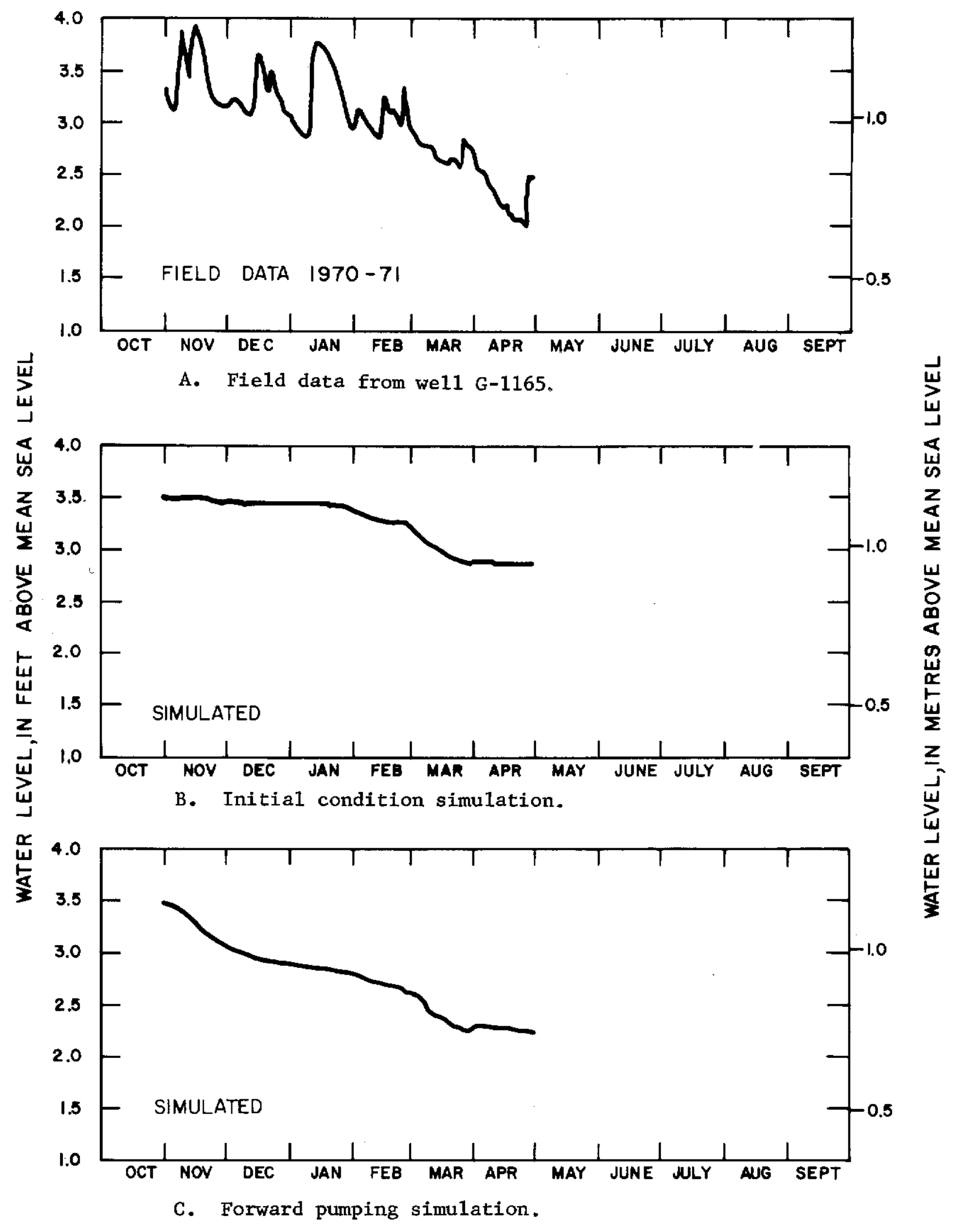

Figure 19.--Hydrographs for ground-water we11 G-1165 and model node $\mathrm{BN}-92$ in test site $\mathrm{AA}$. 


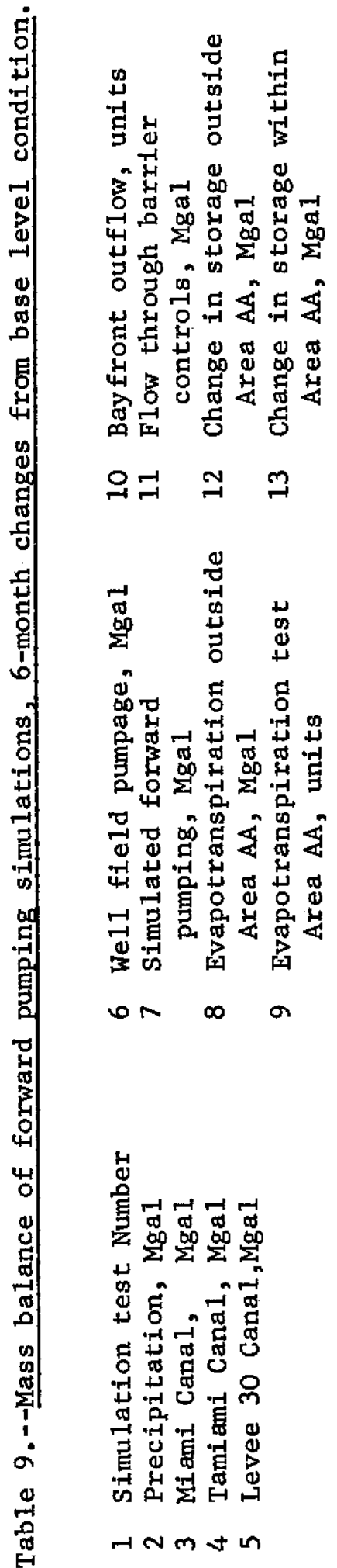

\begin{tabular}{|c|c|}
\hline$m$ & 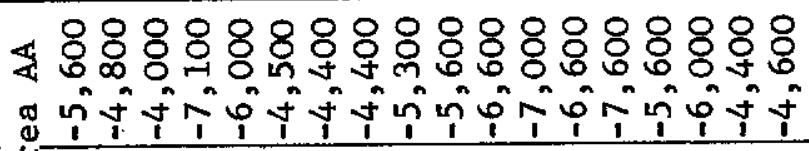 \\
\hline$\underline{\simeq}$ & 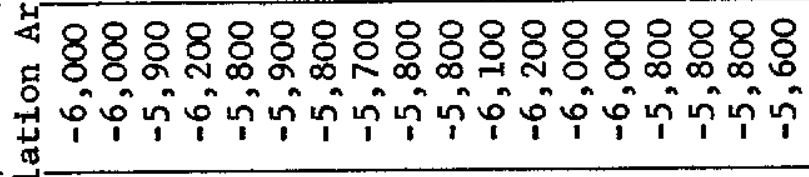 \\
\hline$=$ & 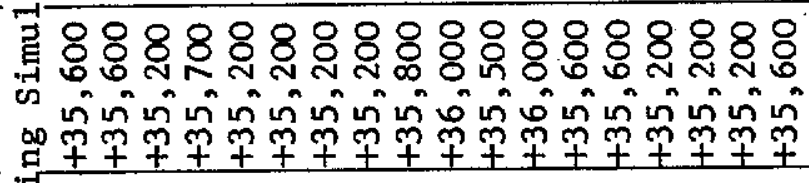 \\
\hline 으 & 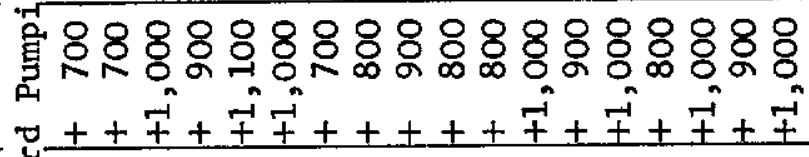 \\
\hline$\sigma$ & 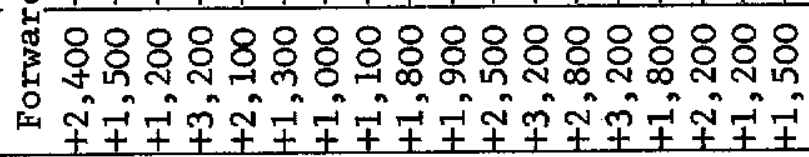 \\
\hline$\infty$ & 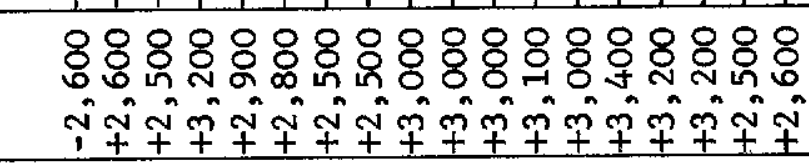 \\
\hline 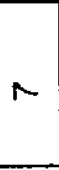 & 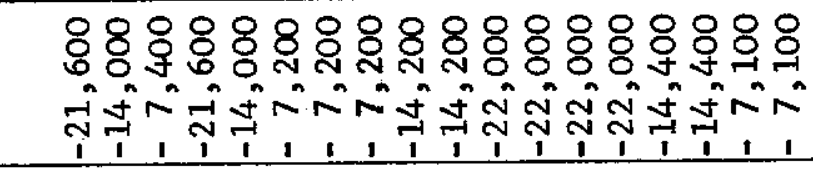 \\
\hline$\varphi$ & 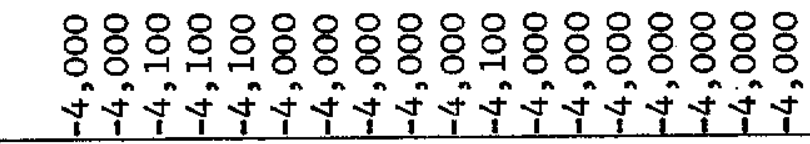 \\
\hline$n$ & 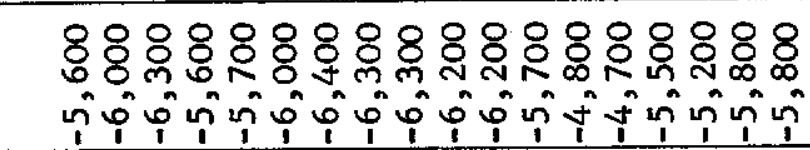 \\
\hline$\nabla$ & 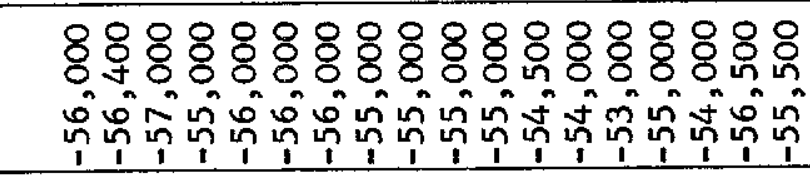 \\
\hline$m$ & 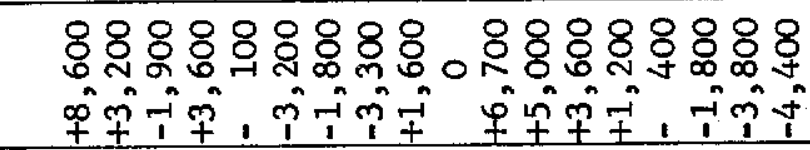 \\
\hline$N$ & 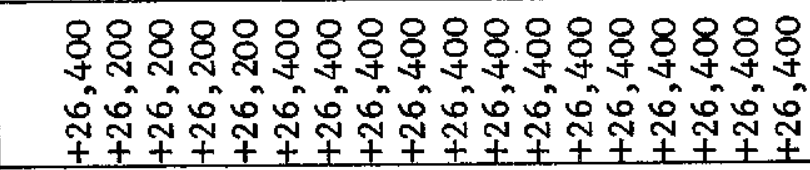 \\
\hline- & 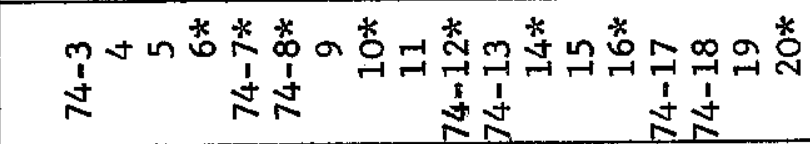 \\
\hline
\end{tabular}




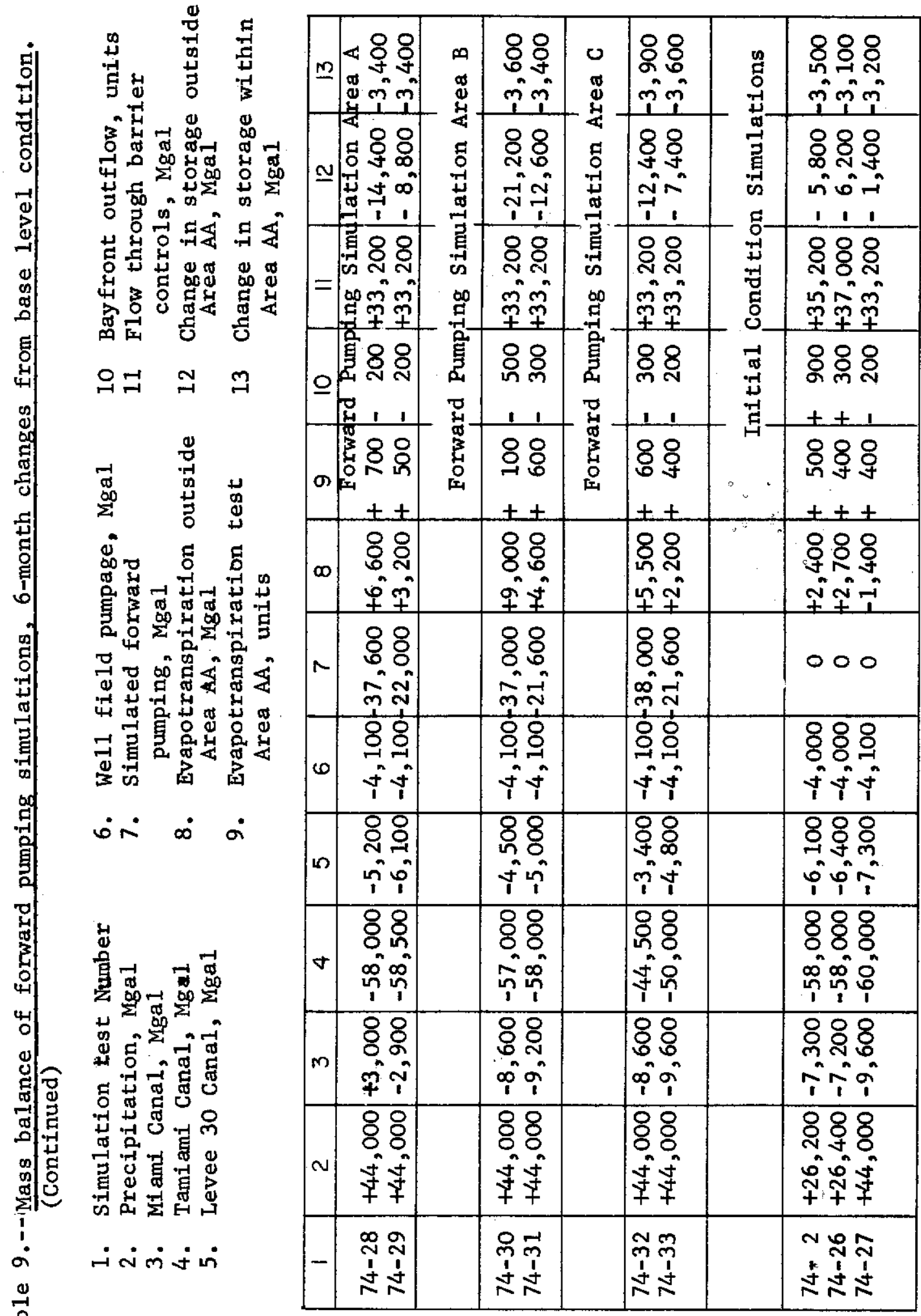




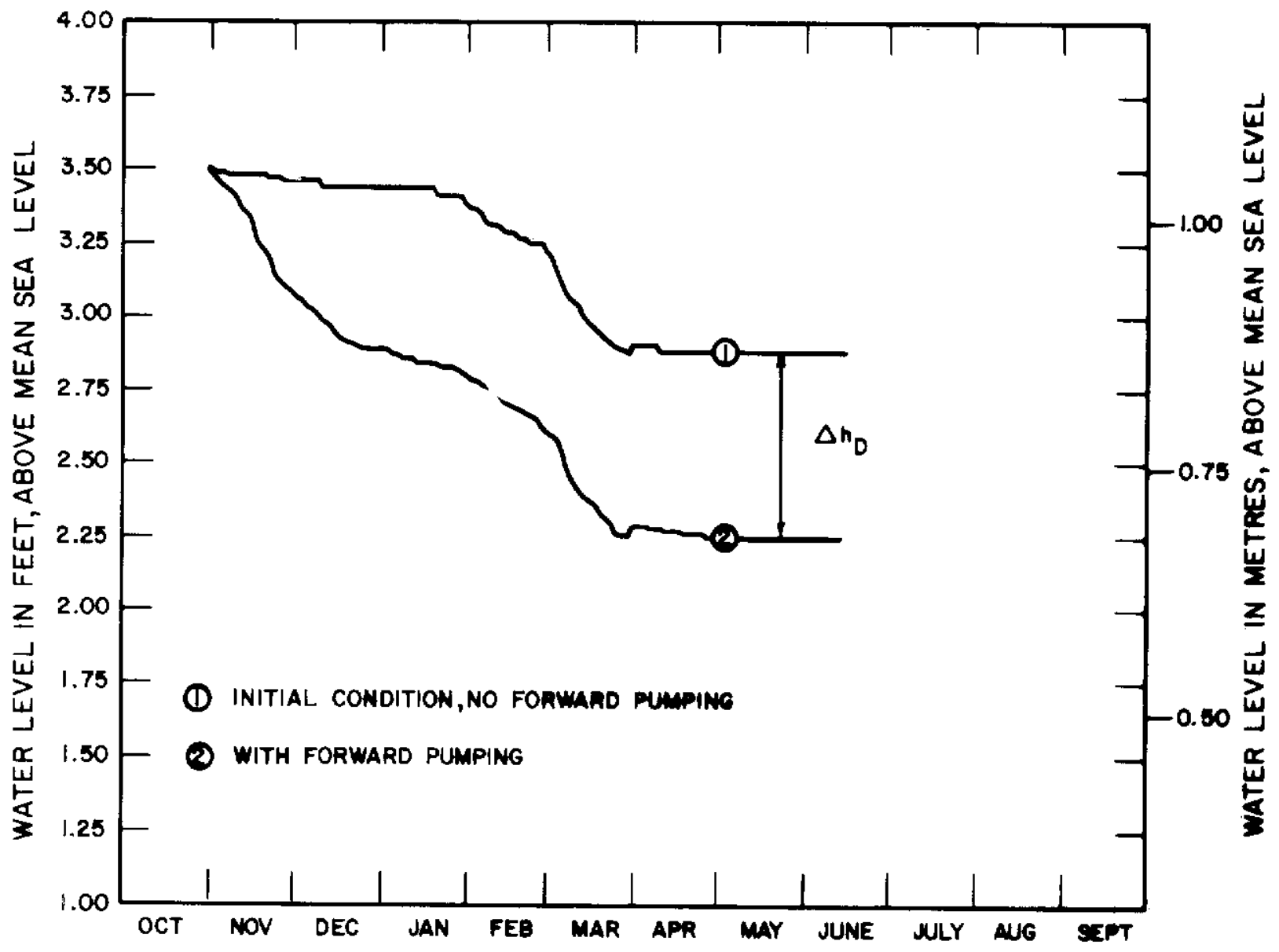

Figure 20.--Effect of forward pumping stress $\left(\Delta \mathrm{h}_{\mathrm{D}}\right)$ observed as a typical mode1 node. 


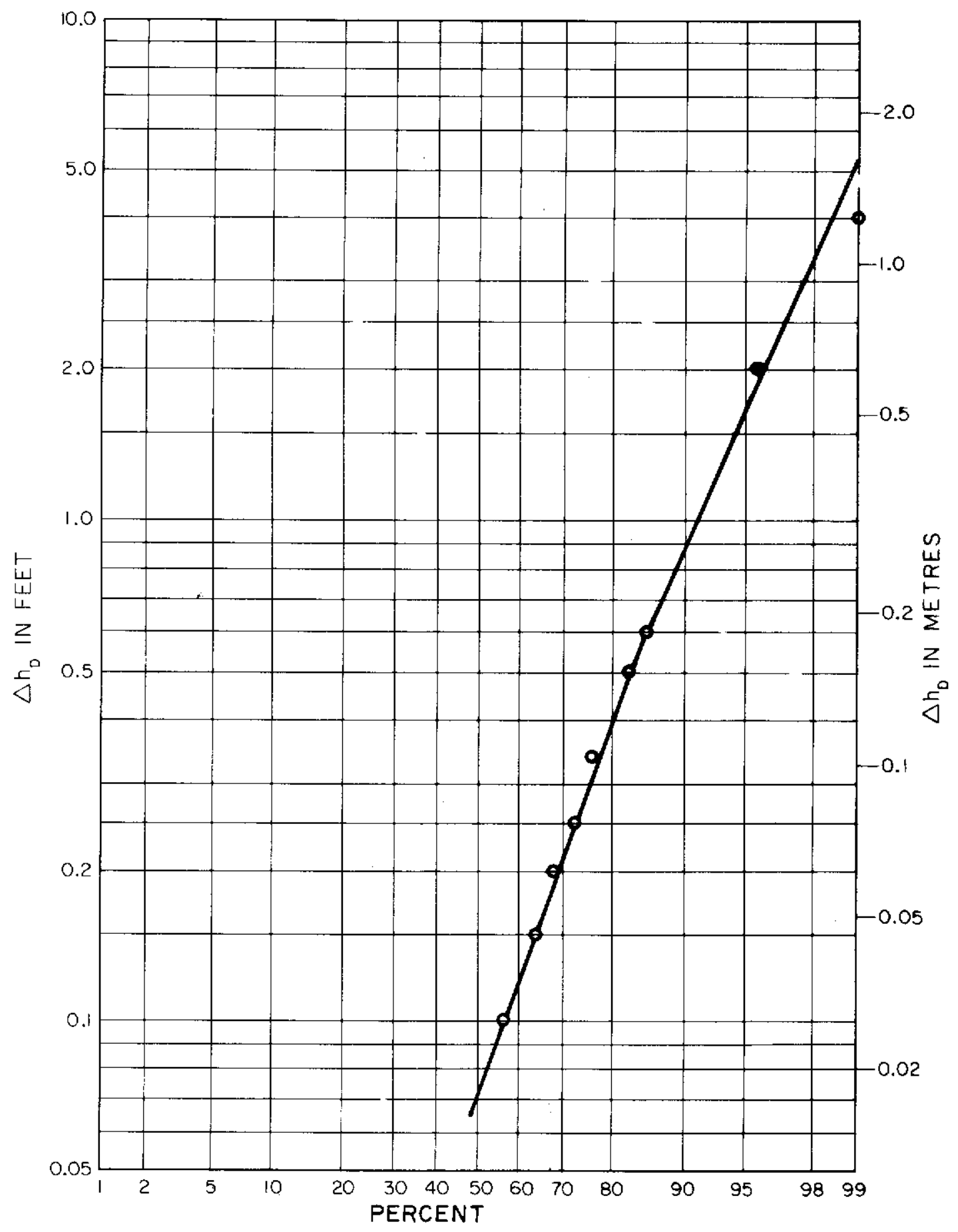

Figure 21.--Percentage of standard sampling area $A A$ for which $\left(\Delta h_{D}\right)$ was equal to or less than the indicated value for forward pumping simulation 74-3. 


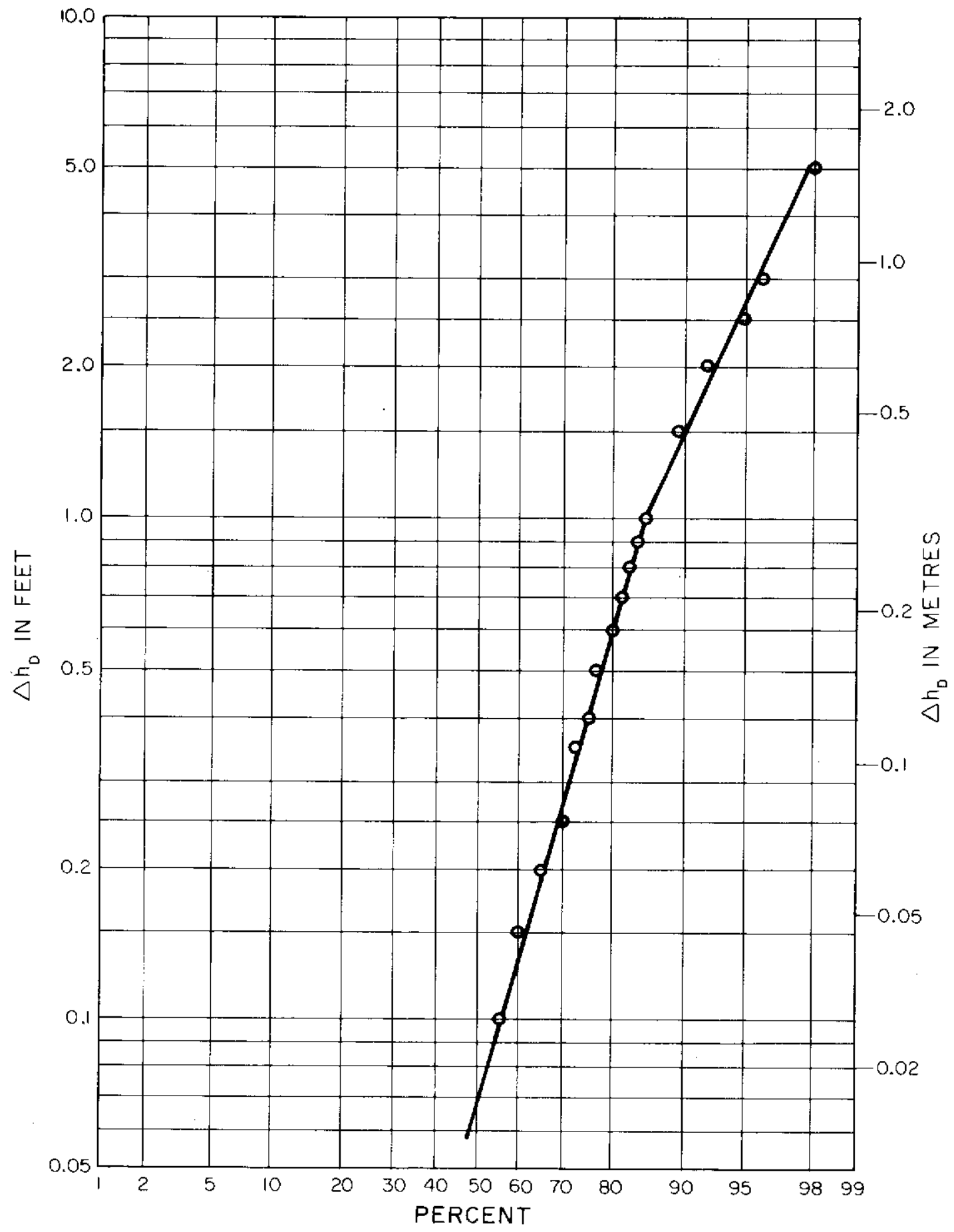

Figure 22.--Percentage of standard sampling area AA for which $\left(\Delta h_{D}\right)$ was equal to or less than the indicated value for forward pumping simulation 74-14. 


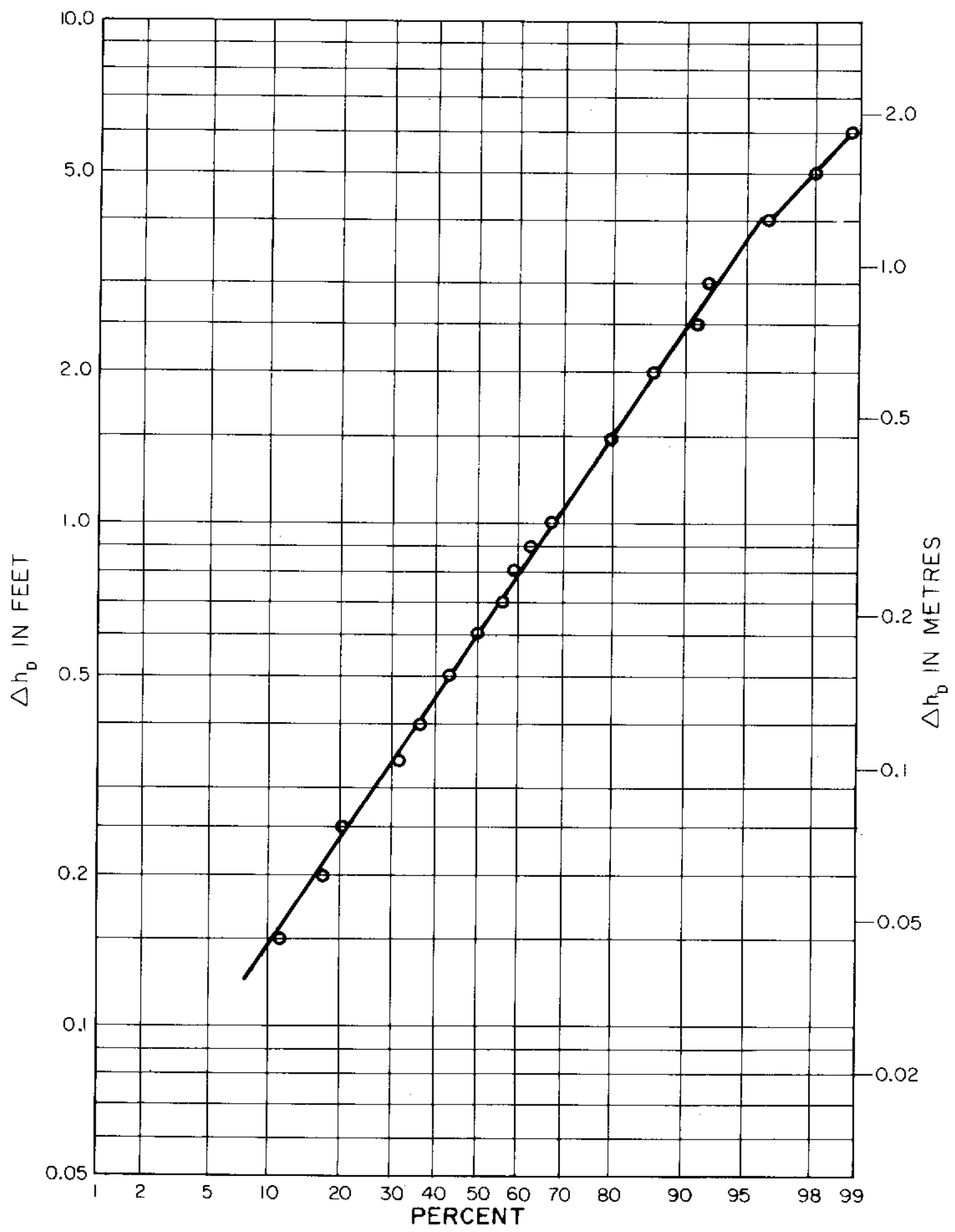

Figure 23.--Percentage of standard sampling area A for which $\left(\Delta h_{D}\right)$ was equal to or less than the indicated value for forward pumping simulation 74-29. 


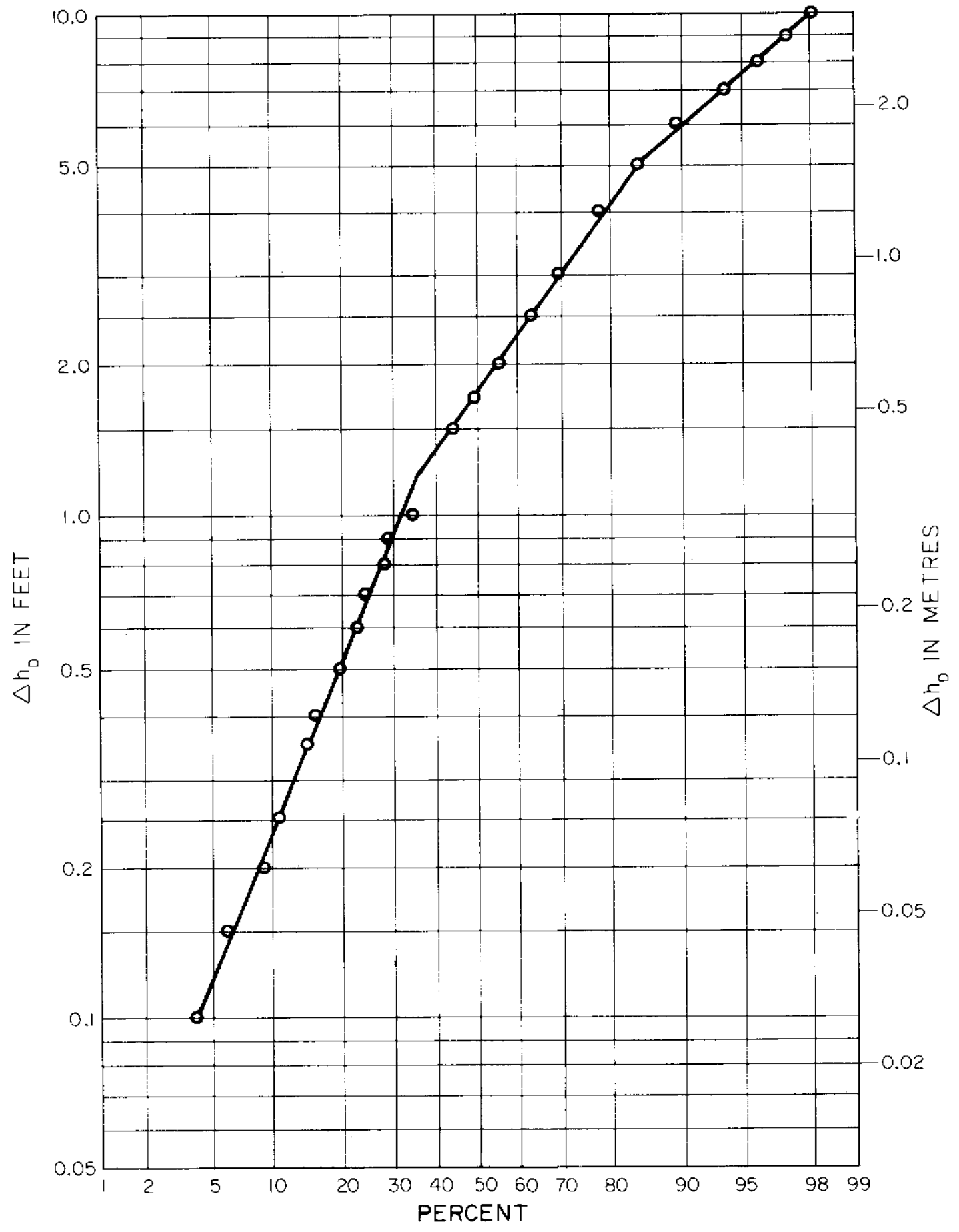

Figure 2.4.--Percentage of standard sampling area B for which $\left(\Delta \mathrm{h}_{\mathrm{D}}\right)$ was equal to or less than the indicated value for forward pumping simulation 74-30. 


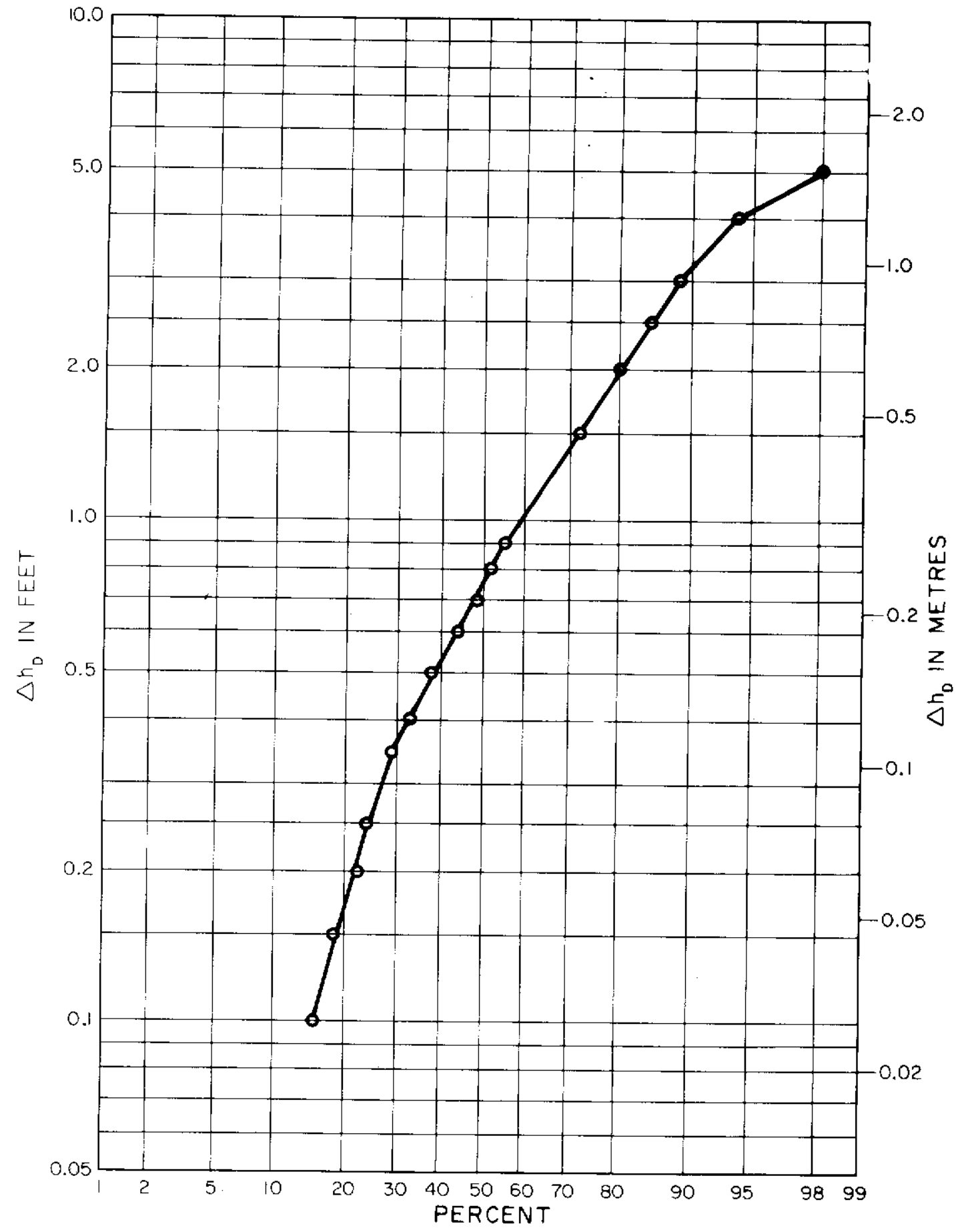

Figure 25.--Percentage of standard sampling area $B$ for which $\left(\Delta \mathrm{h}_{\mathrm{D}}\right)$ was equal to or less than the indicated value for forward pumping
simulation $74-31$. 
The median values of $\Delta h_{D}$ for forward pumping simulations 74-3, 74-6, $74-13,74-14,74-15,74-16,74-29,74-31$ and 74-33 (a11 with simulated pumping rates of $120 \mathrm{Mgal} / \mathrm{d},\left(5.26 \mathrm{~m}^{3} / \mathrm{s}\right)$, range from 0.08 foot $(0.024 \mathrm{~m})$ to 0.8 foot $(0.24 \mathrm{~m})$. The areas affected by median values of drawdown for selected simulations are shown in figures 26-35.

The simulation techniques applied to the electric analog model relate only to the effects that forward pumping will have on changes in ground-water storage and ET losses. A measure of the relative effectiveness of the forward pumping schemes, as defined by the 24 simulation runs in table 7 , is the maximum lowering of ground water that each test site can sustain prior to inducing recirculation from the boundaries. It is assumed that the water being pumped from the ground-water basin and the ET is completely removed from the system. In practice, the pumped ground water could be made a part of the surface water in the canal storage and distribution system.

The total additional ground-water storage space that is shown in table 7 was computed from the difference of the sum of columns 12 and 13 , for each test run and its corresponding initial condition simulation (end of table 9). The appropriate initial condition is that with values in column 2 of table 9 identical to those of the appropriate model run.

Additional aquifer storage space developed by forward pumping ranged from 8 percent to 20 percent of the quantity forward pumped from site AA, but was more than 50 percent of the water pumped from site $B$. The amount of additional storage space created by forward pumping is proportional to the magnitude of lowering of ground-water levels. In addition, water would also be salvaged by reducing evapotranspiration losses.

The simulations for site AA indicate that forward pumping would impose small but measureable additional drawdowns within adjacent municipal well fields. However, because most (60-70 percent) of the water pumped would be recirculated through canals in site $A A$, storage space created for recharge to the aquifer would be minimal. On the other hand, simulations in sites A, B and C showed that as much as 54 percent of the forward-pumped water came from aquifer storage.

The forward pumping simulation in site $B$ which utilized four widely spaced wells was the most effective because the area is remote from canal influence. Figures 25 and $\mathbf{3 3}$ indicate that about half the $225-\mathrm{mi}^{2}\left(583-\mathrm{km}^{2}\right)$ standard sampling area $B$ had $0.8 \mathrm{ft}(0.24 \mathrm{~m})$ drawdown or less, with 4 wells simulating pumping at a rate of $120 \times 10^{6} \mathrm{gal} / \mathrm{d}\left(5.26 \mathrm{~m}^{3} / \mathrm{s}\right)$. At a simulated pumping rate of $210 \times 10^{6} \mathrm{gal} / \mathrm{d}(9.2 \mathrm{~m} / \mathrm{s})$ the median $\Delta \mathrm{h}_{\mathrm{D}}$ was 1.7 feet $(0.5 \mathrm{~m})$ ( $\mathrm{fig} .35$ ) and only 4 percent of standard sampling area $B$ had a decline of water level equal to 0.1 foot $(0.03 \mathrm{~m})$ or less (fig. 24). In contrast, the smallest median value of $\Delta \mathrm{h}_{\mathrm{D}}$ was 0.08 foot $(0.024 \mathrm{~m})$ in site AA (figs. 26 and 29 and figs. 21 and 22 for pumping rates of $120 \times 10^{6}$ ga1/d $\left(5.26 \mathrm{~m}^{3 / \mathrm{s}}\right)$. 


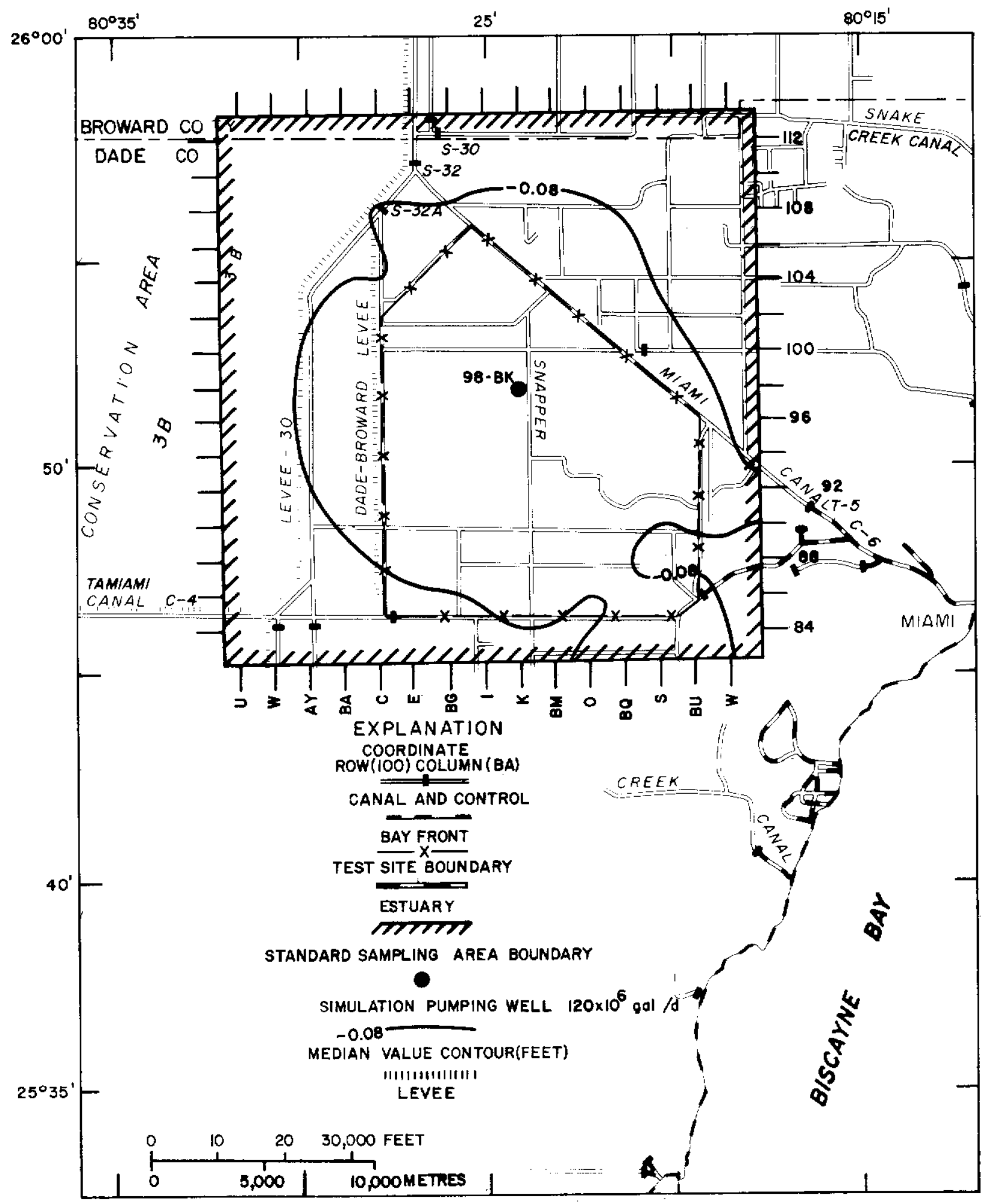

Figure 26.--Median value of head change $\left(\Delta h_{D}\right)$ for forward pumping simulation $74-3$, standard sample area AA. 


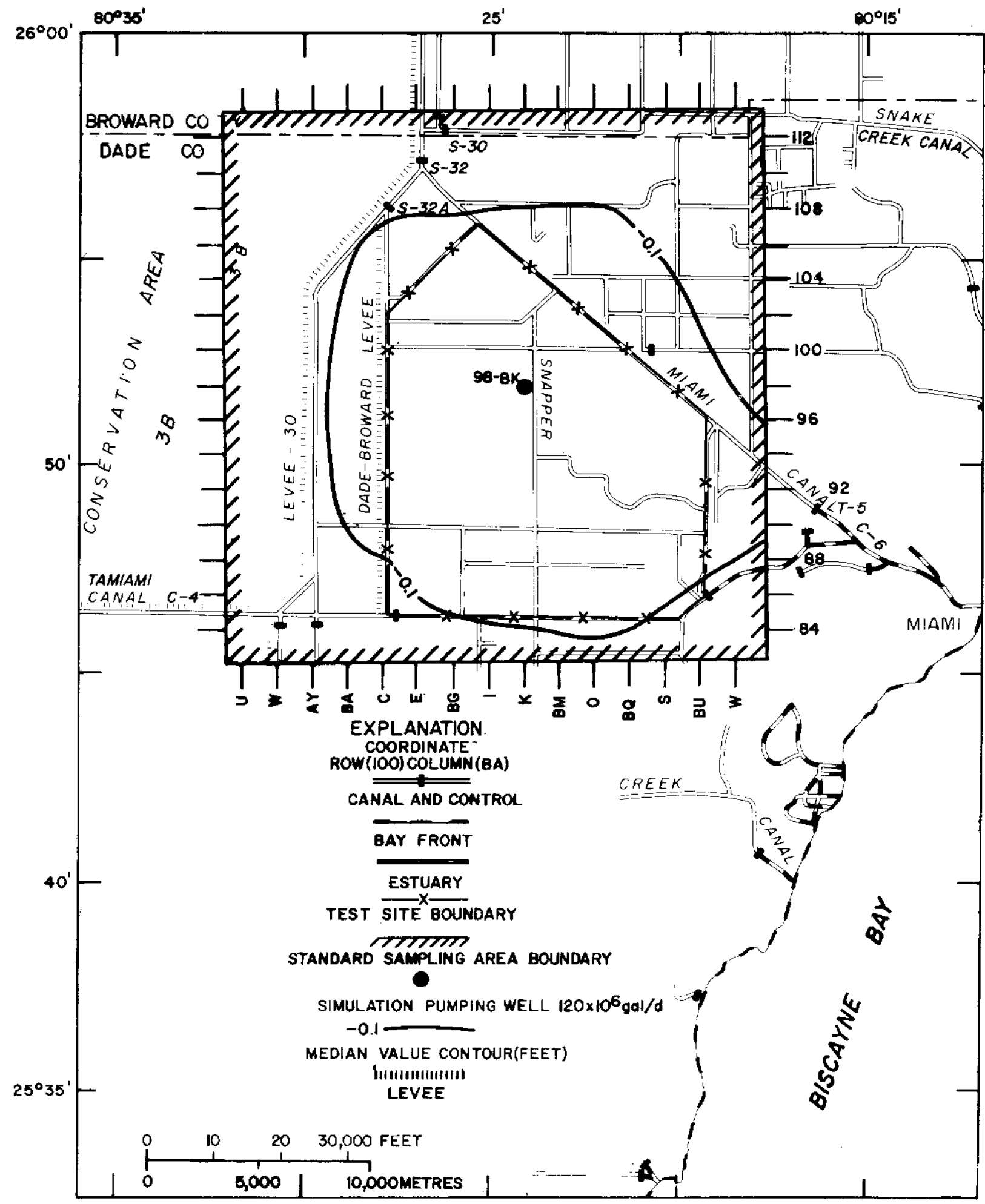

Figure 27.--Median value of head change $\left(\Delta h_{D}\right)$ for forward pumping simulation 74-6, standard sample area AA. 


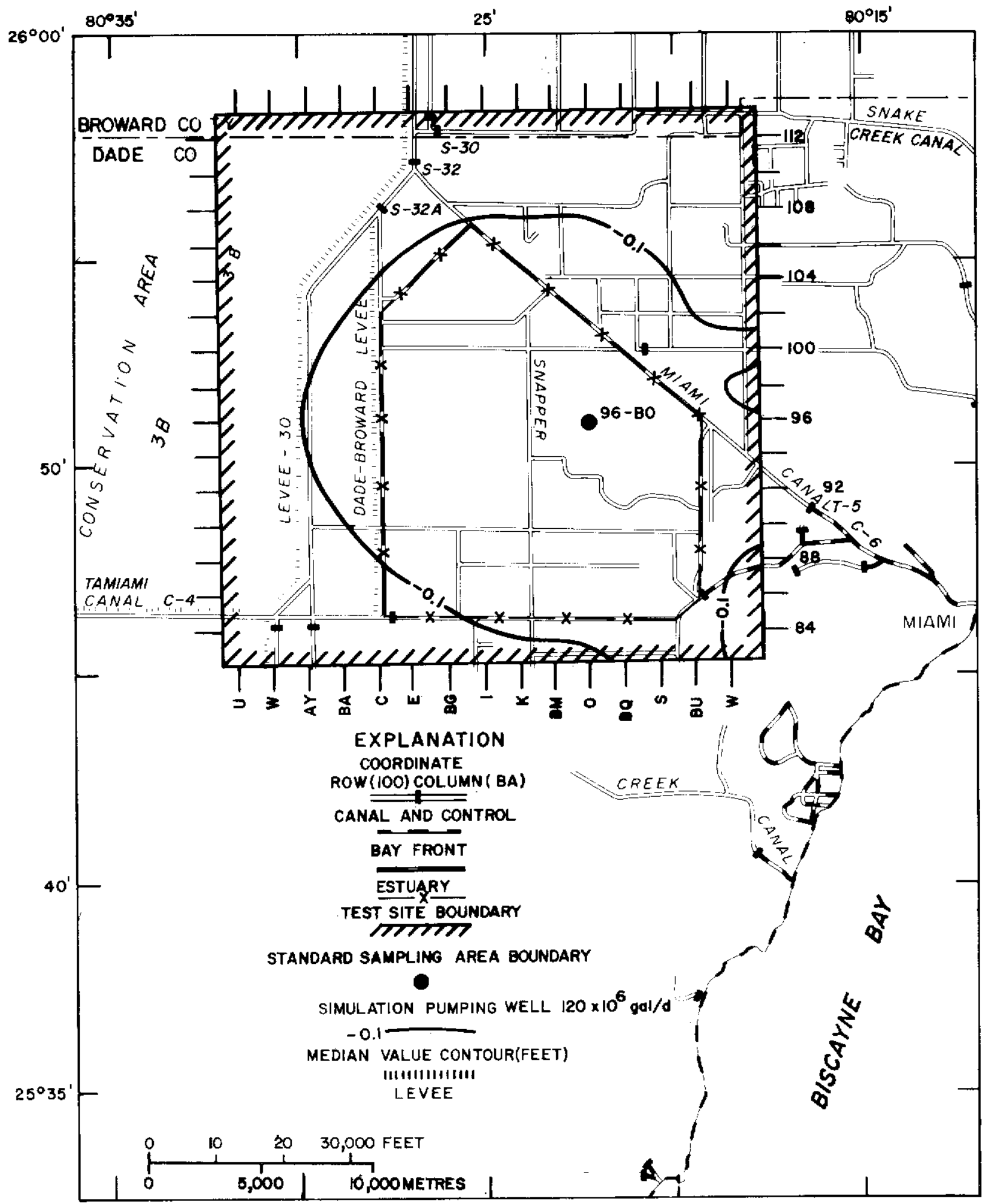

Eigure $28,--$ Median value of head change $\left(\Delta h_{D}\right)$ for forward pumping simulation 74-13, standard $\approx$ mple area $A A$. 


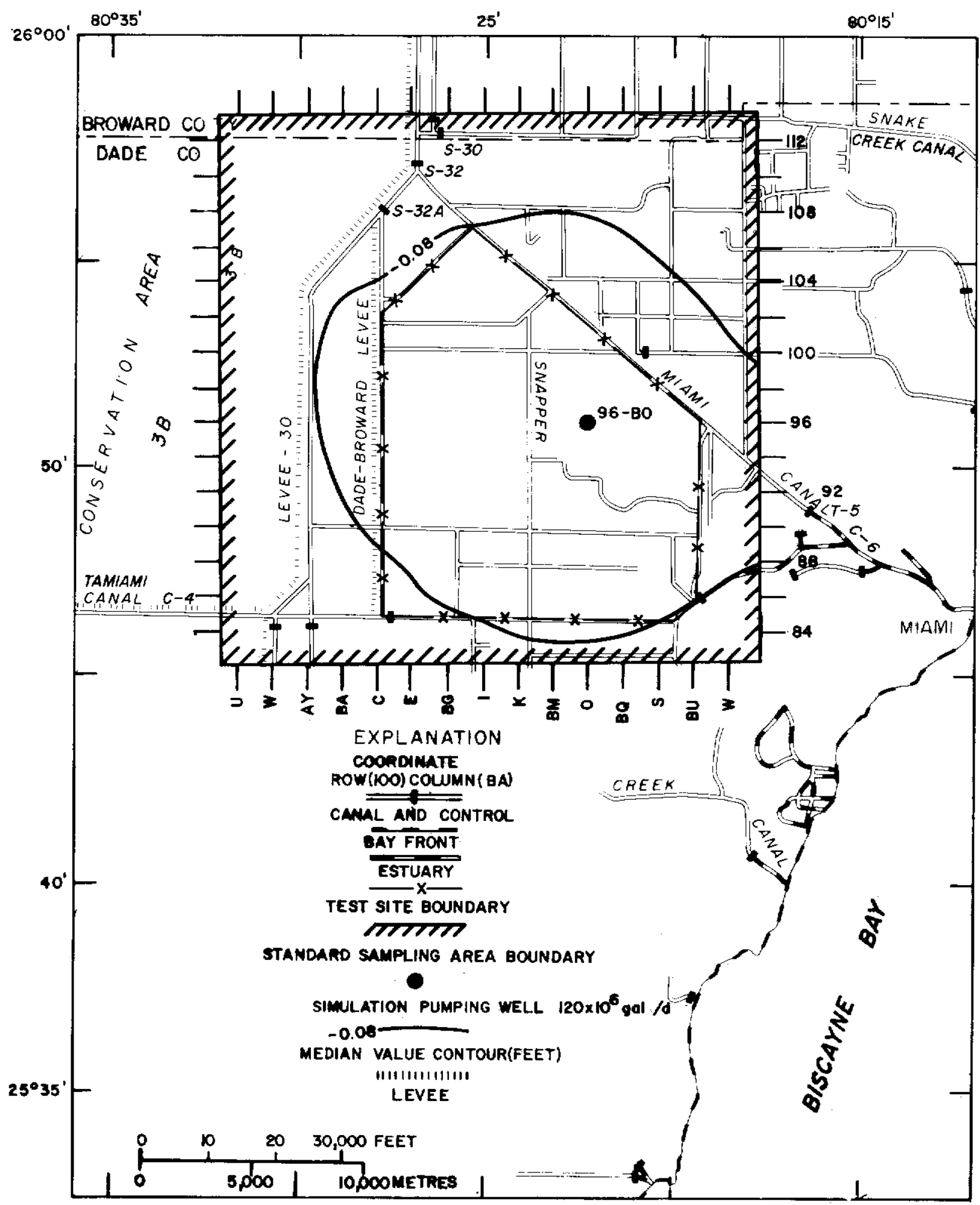

Figure 29.--Median value of head change $\left(\Delta h_{D}\right)$ for forward pumping simulation 74-14, standard sample area $\mathrm{AA}$. 


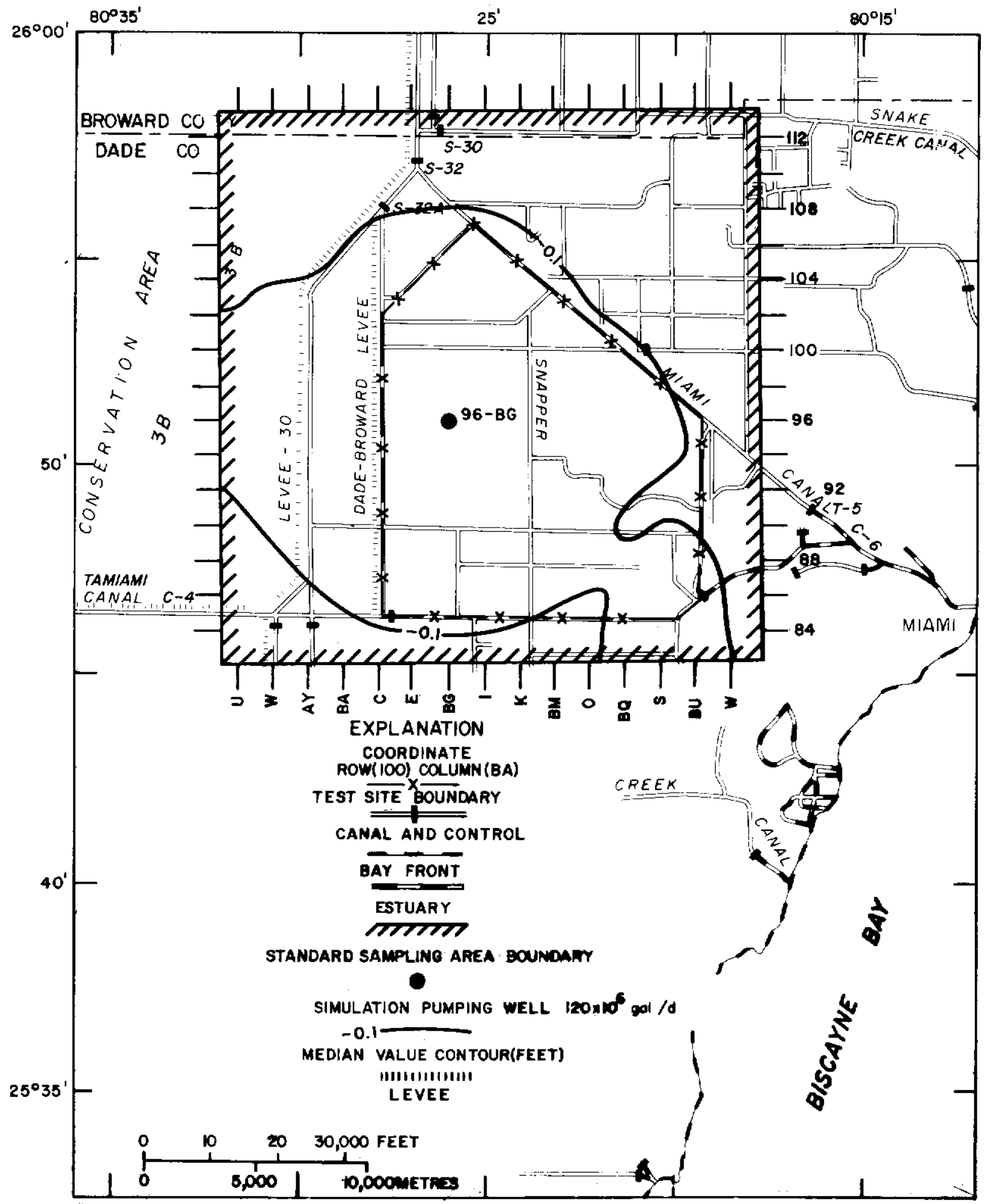

Figure 30.--Median value of head change $\left(\Delta h_{D}\right)$ for forward pumping simulation 74-15, standard sample area AA. 


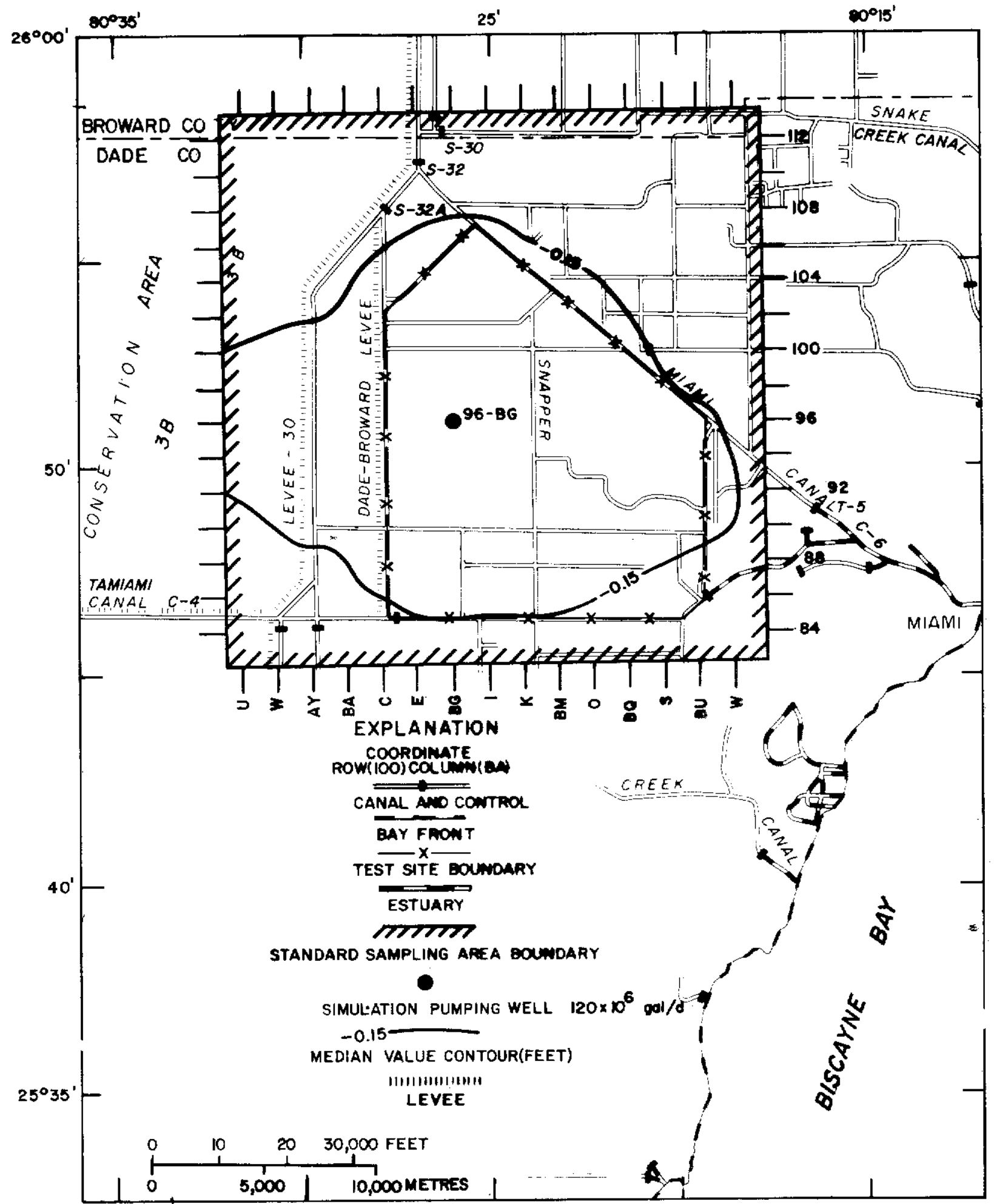

Figure 31.--Median value of head change $\left(\Delta h_{D}\right)$ for forward pumping simulation 74-16, standard sample area AA. 


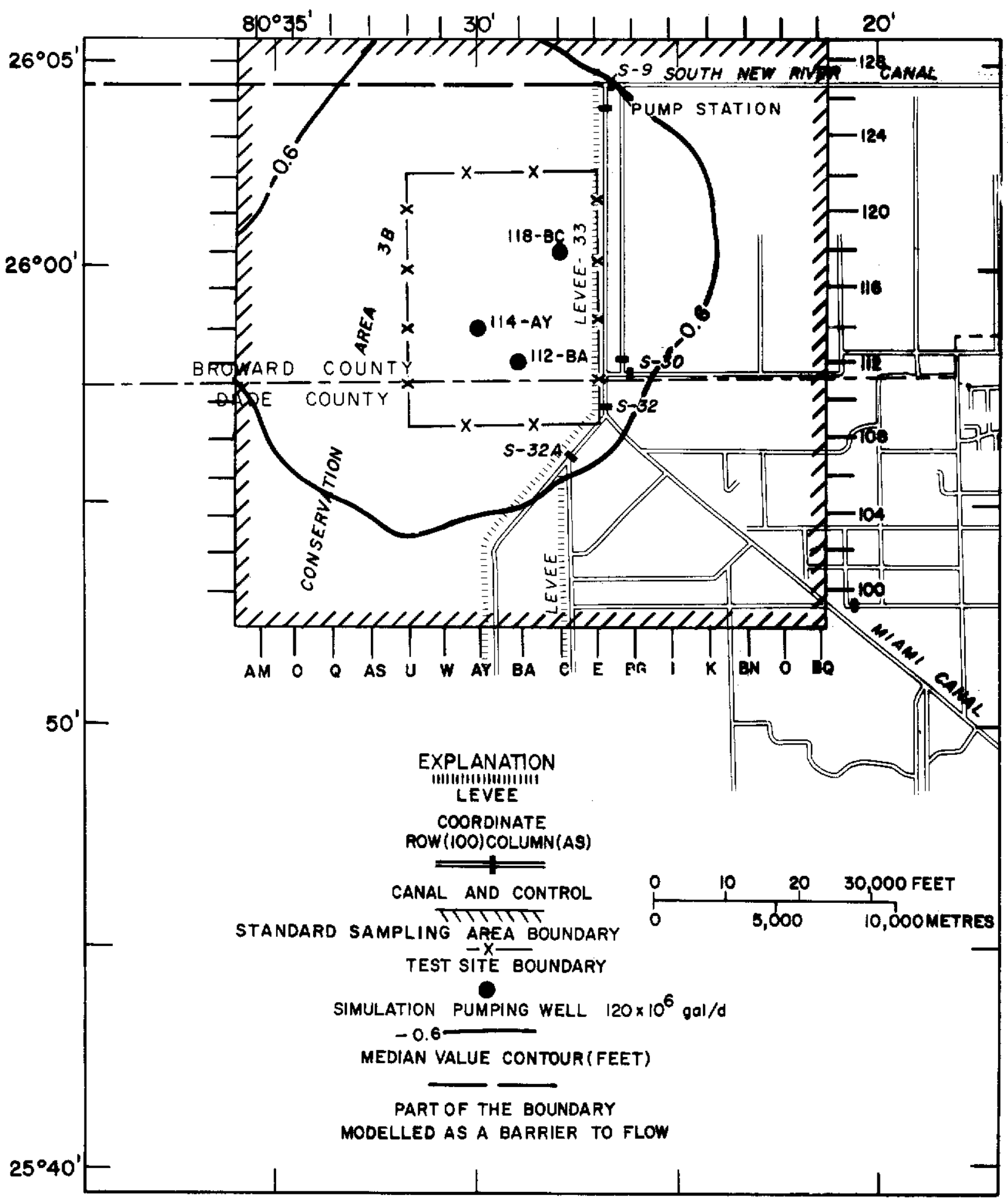

Figure 32.--Median value of head change $\left(\Delta h_{D}\right)$ for forward pumping simulation 74-29, standard sample area $A$. 


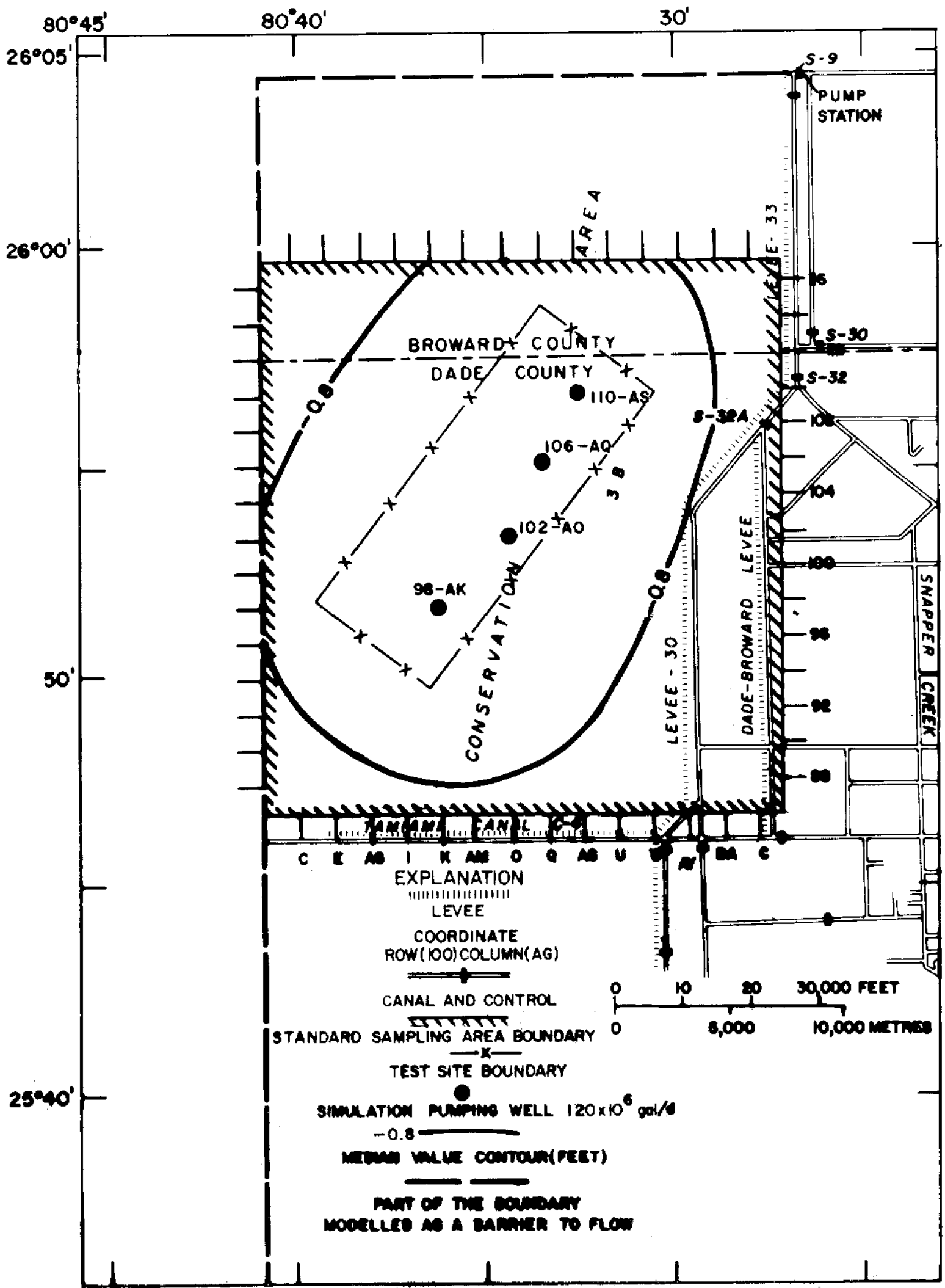

Figure 93.--Median value of head change $\left(\Delta h_{D}\right)$ for forward pumping simulation 74-31, standard sample area $B$. 


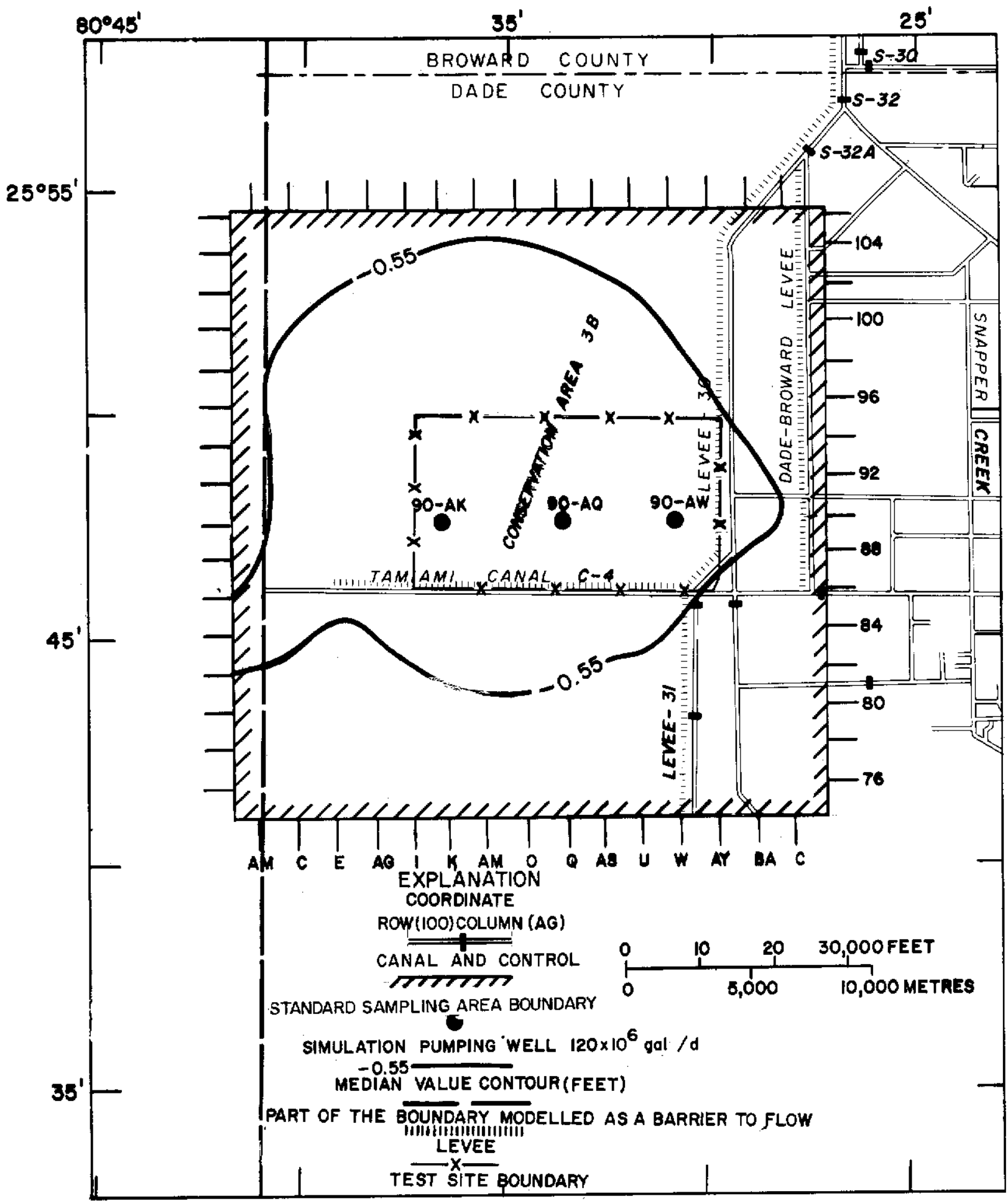

Figure 34.--Median value of head change $\left(\Delta \mathrm{h}_{\mathrm{D}}\right)$ for forward pumping simulation 74-33, standard sample area $\mathrm{C}$. 


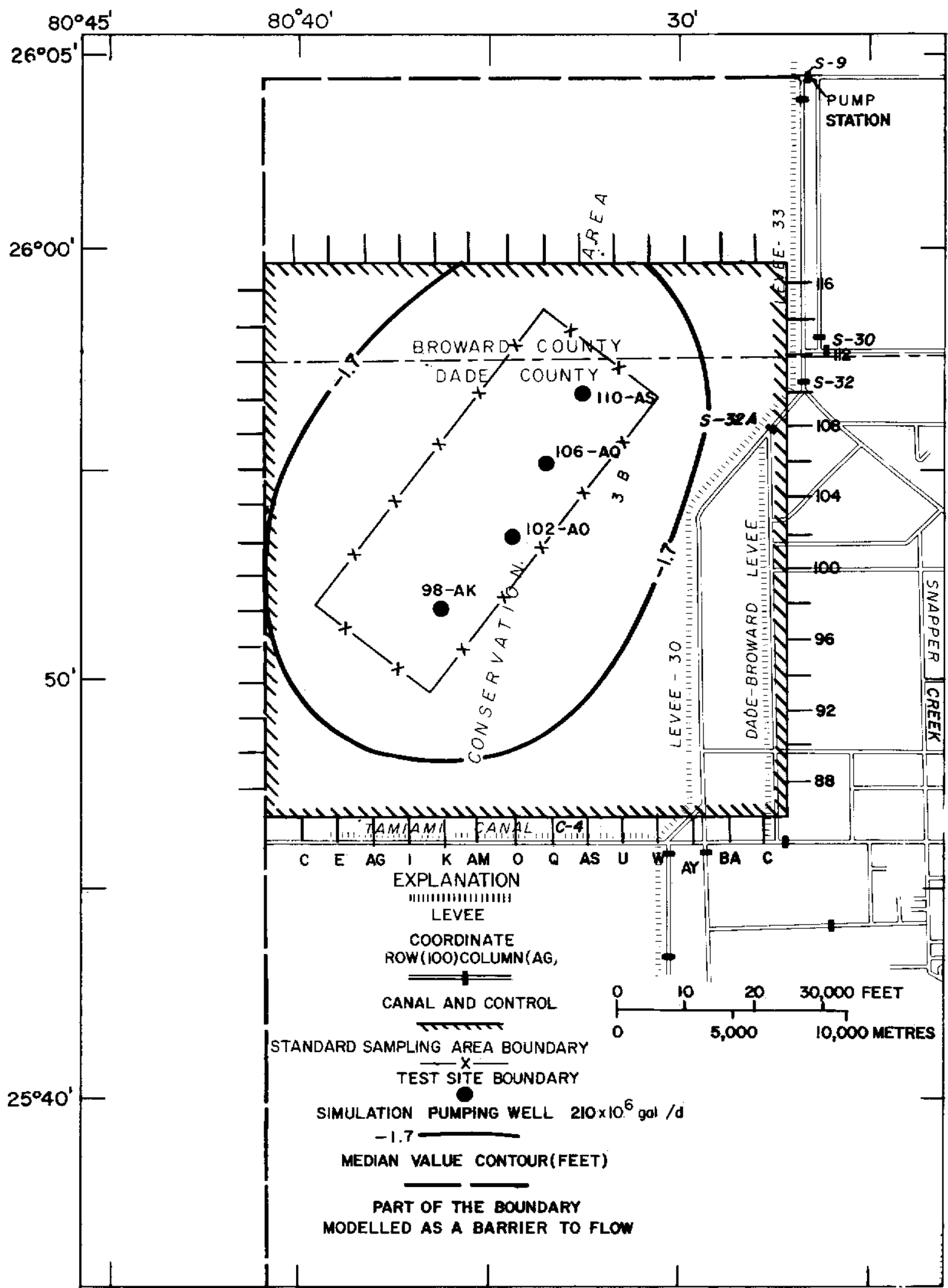

Figure 35.--Median value of head change $\left(\Delta h_{\mathrm{D}}\right)$ for forward pumping simulation 74-30, standard sample area $B$. 


\section{Summary}

Forward pumping is a scheme for using groundwater from remote inland areas to partly satisfy the demands in the heavily urban coastal areas of Dade County, Fla., through induced canal infiltration near well fields and maintaining coastal water levels during dry season. Water levels would be lowered in areas selected for forward pumping, thereby reducing the natural losses from ET and creating additional storage space for ground-water recharge. It is assumed that deficits in ground-water storage can be satisfied, in part, by increased recharge from excess rainfall or by changes in the water level along the boundaries. If such is not the case, additional cumulative water-leve1 decline could result in the area in which pumping occurs.

The electric analog mode1 was programmed to simulate a forward pumping scheme and the changes in ground-water storage were considered most indicative of basin response to this stress.

Analog model studies showed that forward pumping from sites dissected by or adjacent to canals produced minimal lowering of aquifer water levels, because of recirculation, whereas pumping from sites remote from canals produced widespread lowering and maximum storage space for potential aquifer recharge. Storage made available for replenishment, after pumping at a rate of $120 \mathrm{Mgal} / \mathrm{d}\left(5.26 \mathrm{~m}^{3 / \mathrm{s}}\right)$, ranged from 11 to 52 percent of the total water pumped. 


\section{REFERENCES}

Appe1, C. A., 1973, Electrical-analog model study of a hydrologic system in southeast Florida: U. S. Geol. Survey open-file report, 51 p.

Benson, M. A. and Gardner, R. A., 1974, the 1971 Drought in south Florida and its effect on the hydrologic system: U. S. Geo1. Survey WaterResources Inv. 12-74, $46 \mathrm{p}$.

Hu11, J. E. and Wimberly, E. T., 1972, Hydrologic conditions during 1971 in Dade County, Florida: U. S. Geo1. Survey open-file report.

Klein, Howard, and Sherwood, C. B., 1961, Hydrologic conditions in the vicinity of Levee 30, northern Dade County, Florida: Florida Geol. Survey Rept. Inv. 24, pt. 1, 24 p.

Kohout, F. A, and Leach, S. D., 1964, Salt-water movement caused by controldam operation in the Snake Creek Canal, Miami, Florida: Florida Geol. Survey Rept. Inv. 24, pt. 4, 49 p.

Kohout, F. A. and Hartwe11, J. H., 1967, Hydrologic effects of Area B flood control plan on urbanization of Dade County, Florida, Florida Geol. Survey Rept. Inv. 47, pt. 3, 61 p.

Leach, S. D. and Sherwood, C. B., 1963, Hydrologic studies in the Snake Creek Canal area, Dade County, Florida, Florida Geol. Survey Rept. Inv. $24,33 \mathrm{p}$.

Parker, G. G., Ferguson, G. E., Love, S. K., and others, 1955, Water resources of southeastern Florida, U. S. Geol. Survey Water-Supply Paper 1255, $965 \mathrm{p}$.

Sherwood, C. B. and Leach, S. D., 1962, Hydrologic studies in the Snapper Creek Canal area, Dade County, Florida, Florida Geol. Surv. Rept. Inv. 24, pt. 2, 32 p.

Stewart, E. H., and Mi11s, W. C., 1967, Effect of depth to water table and plant density on evapotranspiration rate in southern Florida: Trans. Am. Soc. Agr. Engineer, v. 10, no. 6, p. 746-747. 